\title{
Copyright
}

by

Carrie Ann Barth Bredow

2012 
The Dissertation Committee for Carrie Ann Barth Bredow Certifies that this is the approved version of the following dissertation:

\section{Chasing Prince Charming: Partnering Consequences of Holding Unrealistic Standards for a Spouse}

\section{Committee:}

Ted L. Huston, Supervisor

Timothy J. Loving

Lisa A. Neff

Edward R. Anderson

Anita L. Vangelisti 


\title{
Chasing Prince Charming: Partnering Consequences of Holding Unrealistic Standards for a Spouse
}

\author{
by \\ Carrie Ann Barth Bredow, B.S.; M.A.
}

\author{
Dissertation \\ Presented to the Faculty of the Graduate School of \\ The University of Texas at Austin \\ in Partial Fulfillment \\ of the Requirements \\ for the Degree of
}

Doctor or Philosophy

The University of Texas at Austin

August 2012 


\section{Acknowledgements}

I would like to thank my adviser, Ted Huston, for his extensive help, support, and mentorship, not only during the process of writing this document, but throughout my time as a graduate student at UT. I also thank the members of my committee and Erin Crockett for their support and helpful feedback. And finally, I want to thank and acknowledge my wonderful husband, Andrew, for his unwavering support throughout the last 6 years (and especially the last two years following the birth of our beautiful twin daughters)! We are a team in every sense of the word and I would not be where I am today without him! 


\title{
Chasing Prince Charming: Partnering Consequences of Holding Unrealistic Standards for a Spouse
}

\author{
Carrie Ann Barth Bredow, Ph.D. \\ The University of Texas at Austin, 2012
}

Supervisor: Ted L. Huston

\begin{abstract}
Although social scientists studying mate selection have generally assumed that people's standards for a marriage partner shape their marital behavior, systematic investigations of the role of mate standards in partnering have been rare. Using survey data collected from 502 unmarried individuals and their peer informants, the present study used a novel, residual-based approach to quantify the attainability (rather than the absolute stringency) of people's standards for a spouse. Regression analyses using this index of the attainability of people's standards revealed that holding less realistic standards for a marriage partner was associated with greater difficulty establishing satisfying romantic relationships, lower expectations to marry one's current partner, and lower levels of psychological and behavioral investment in finding a suitable partner and marrying. Curiously, the attainability of people's spousal standards did not predict their general beliefs about whether they will eventually marry. Overall, these findings strongly support the idea that holding less realistic standards for a spouse shapes people's partnering experiences in ways that may deter their future entry into marriage.
\end{abstract}




\section{Table of Contents}

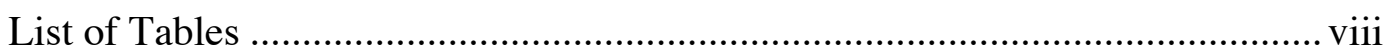

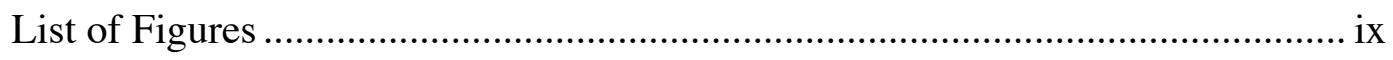

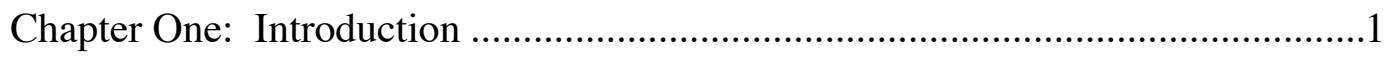

Theoretical Perspectives on Mate Standards and Partnering ..........................2

Empirical Evidence: Do Mate Standards Really Matter? .................................

Overview of the Current Investigation ........................................................

Chapter Two: Method ...................................................................................16

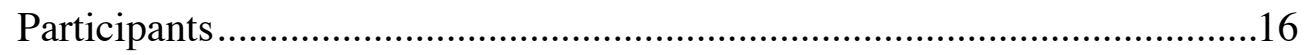

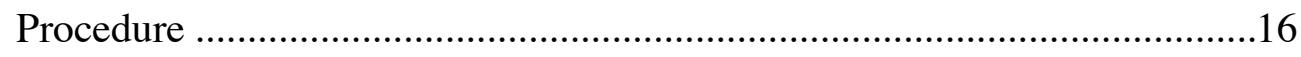

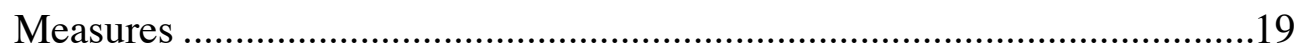

Minimum standards for a marriage partner. …………………….......19

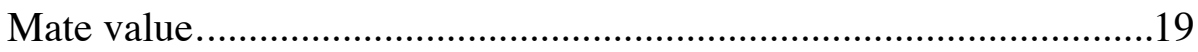

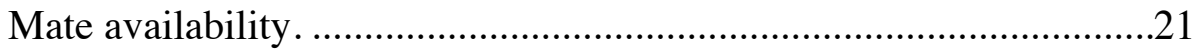

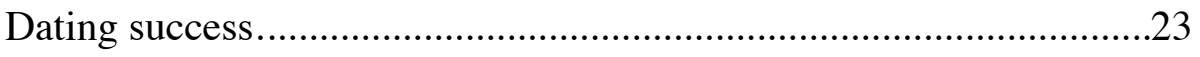

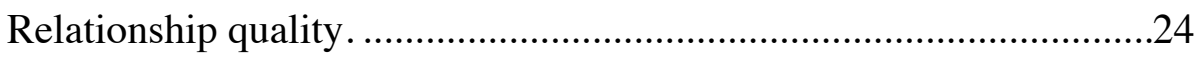

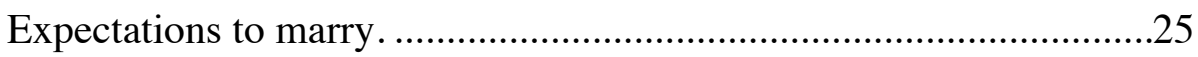

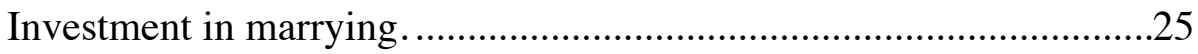

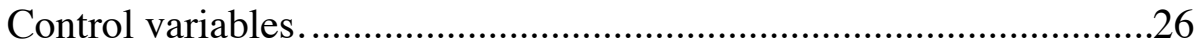

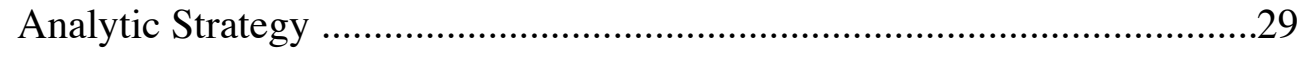

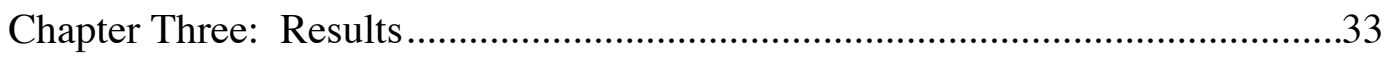

Calculating Unrealistic Standards ..............................................................33

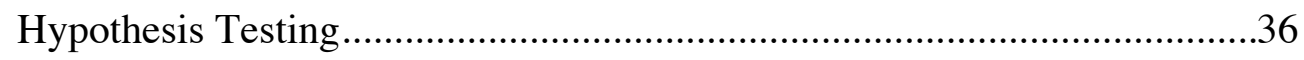

Descriptive statistics. ........................................................................36

Unrealistic standards and dating success..............................................40

Unrealistic standards and relationship quality.....................................42

Unrealistic standards and expectations to marry. ..................................42

Unrealistic standards and investment in marrying ................................47 


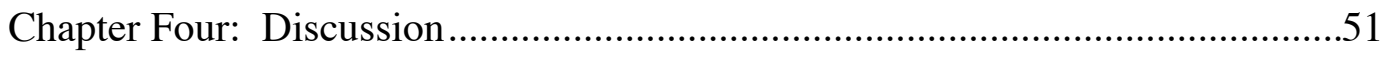

Calculating Unrealistic Spousal Standards ................................................51

Unrealistic Standards and Dating/Relationship Success................................56

Unrealistic Standards and Expectations to Marry/

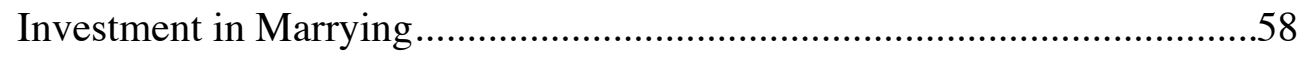

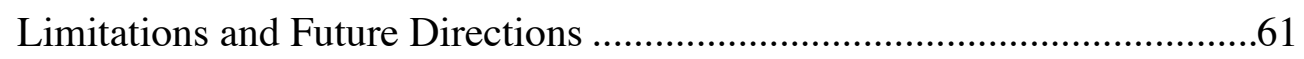

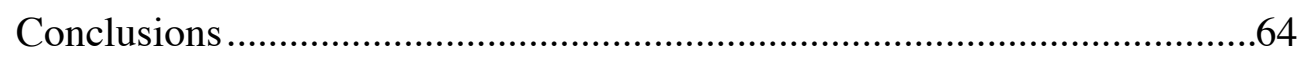

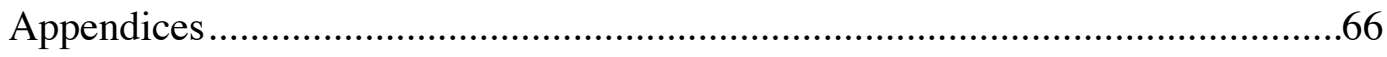

Appendix A: Standards for a Marriage Partner .........................................66

Appendix B: Mate Value .......................................................................67

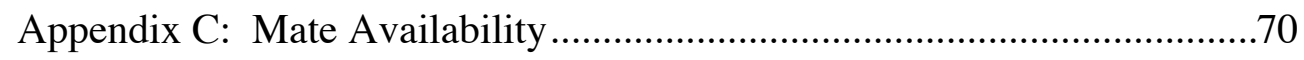

Appendix D: Dating Success ...................................................................75

Appendix E: Relationship Quality ............................................................

Appendix F: Expectations to Marry .............................................................79

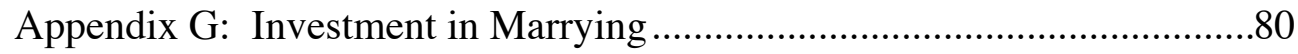

Appendix H: Control Variables .................................................................82

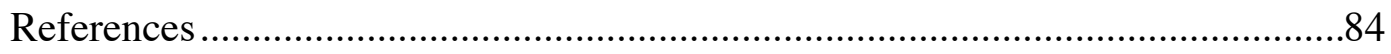

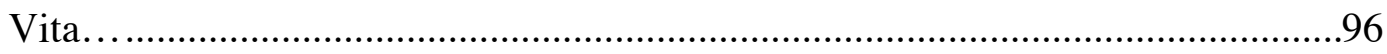




\section{List of Tables}

Table 1: Descriptive Statistics for Self- and Informant-Ratings of Mate Value and Mate Availability ................................................30

Table 2: Correlations and Descriptive Statistics for Regression Models .............38

Table 3: Regression Analyses Predicting Dating Success from

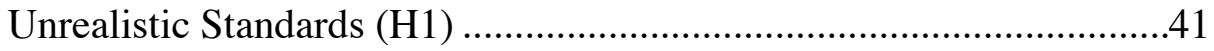

Table 4: Regression Analyses Predicting Relationship Quality from Unrealistic Standards $(\mathrm{H} 2)$................................................43

Table 5: Regression Analyses Predicting Expectations to Marry from Unrealistic Standards (H3a) .............................................45

Table 6: Regression Analyses Predicting Psychological and Behavioral Investment from Unrealistic Standards (H4a) .................................48 


\section{List of Figures}

Figure 1: Conceptual Model for Assessing Unrealistic Standards for

a Marriage Partner............................................................................10

Figure 2: Latent Interaction Model Quantifying Unrealistic Standards

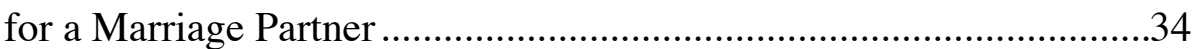

Figure 3: Graph of Mate Value $\times$ Mate Availability Interaction

Predicting Mate Standards ...................................................................35

Figure 4: Graph of $\mathrm{Age}^{2} \times$ Unrealistic Standards Interaction Predicting

People's Expectations to Marry their Current Partners.

Figure 5: Graphs of Interactions between Unrealistic Standards and (a) Age

and (b) Relationship Experience in Predicting Behavioral

Investment in Partnering.... 


\section{Chapter One: Introduction}

Over the last few decades, the American family has undergone a variety of striking changes, including an increasing tendency for individuals to delay entry into marriage or to sometimes never marry at all (Goldstein \& Kenney, 2001; Schoen \& Standish, 2001). Social scientists have posited numerous theories to account for this "retreat from marriage," including economic (e.g., Becker, 1981; Moffitt, 2002), structural (e.g., Lichter, McLaughlin, Kephart, \& Landry, 1992; Wilson, 1987), and social/cultural (e.g., Axinn \& Thornton, 2000; Bulcroft \& Bulcroft, 1993) explanations. One explanation that has received surprisingly little empirical attention - despite its anecdotal popularity - is the hypothesis that cultural changes in the meaning of marriage over the last few decades have led Americans to embrace high, sometimes unattainable, standards for marriage (Bulcroft \& Bulcroft, 1993; Cherlin, 2004; Coontz, 2005; GibsonDavis, Edin, \& McLanahan, 2005). From this perspective, culture-wide endorsement of the ideal that marriage should be one's most intimate and fulfilling adult relationship coupled with the increasingly voluntary nature of marriage itself - has encouraged individuals to set a high bar for what constitutes a marriageable partner and to refrain from marrying if this bar cannot be met.

Although a fair amount of qualitative work has implicated unrealistically high spousal standards as a factor contributing to the some people's decisions not to marry (e.g., Edin \& Kefalas, 2005; Gibson-Davis et al., 2005; Lewis \& Moon, 1997), systematic investigations of the role of mate standards in people's partnering and marital decisionmaking have been rare. In fact, despite an abundance of studies examining the qualities people say they want in a long-term partner (e.g., Buss, Shackelford, Kirkpatrick, \& Larsen, 2001; Fletcher, Simpson, Thomas, \& Giles, 1999), very little is known about the 
extent to which the mate criteria people report influence their concurrent or future partnering behaviors. Are individuals who embrace less "realistic" standards for a marriage partner actually more likely than others to have difficulty in the marriage market and to choose to postpone or forgo marriage? The proposed research seeks to address this question and fill in gaps in the literature on mate selection by (a) developing a model for assessing the attainability of people's reported criteria for a marriage partner and (b) examining whether holding less realistic spousal standards is associated with attitudes and behaviors that are indicative of partnering difficulties and a reduced likelihood of marrying.

\section{Theoretical Perspectives on Mate Standards and Partnering}

Several prominent theories of mate selection and marital timing suggest that the attainability of people's criteria for a marriage partner plays an important role in determining their partnering outcomes. According to social exchange theorists, for example, the process of long-term mate selection resembles a social marketplace in which individuals seek to obtain the best (i.e., most rewarding) partner possible given what they have to offer in return (Blau, 1964; Edwards, 1969; Murstein, 1976). Generally speaking, potential partners are expected to be more rewarding and less costly to the extent that they possess attributes that match people's collective image of the ideal long-term mate - someone who is stunningly beautiful, genuinely kind, and independently wealthy (e.g., Fletcher et al., 1999). But not everyone can partner with a "perfect 10". Because individuals all want to secure the most desirable partner they can,

people are likely to be rejected by romantic prospects who are considerably more marriageable than themselves. From this perspective, individuals who hold mate 
standards that closely approximate their own value as a partner should be more successful at partnering than those who seek to "marry up."

Evolutionary models of mate selection similarly posit that people's standards for a long-term partner should influence their ability to secure a partner to marry (e.g., Penke, Todd, \& Lenton, 2008). Indeed, the notion that mate preferences shape people's partnering behavior is central to the evolutionary perspective, which presumes that people's mating choices are driven by innate psychological mechanisms that evolved, in the form of mate preferences, to help our ancestors solve adaptive problems related to survival and reproduction (Buss, 1988; Buss, 1994; Cosmides \& Tooby, 1992). Although all individuals are motivated to seek out partners who will enhance their reproductive success - namely those possessing attributes that reflect good genetic fitness and the ability and willingness to invest in future offspring (e.g., Buss, 1989) - suitors are not equally equipped to compete for the most desirable spouses. Rather than wasting valuable time and resources vying for partners who are "out of their league," it is reproductively adaptive for people to take stock of their own value as a mate and to develop selection criteria that reflect this self-appraisal (Kenrick, Groth, Trost, \& Sadalla, 1993). The more accurate the calibration of their preferences, the more (reproductively) successful individuals are expected to be (e.g., Sloman \& Sloman, 1988). Thus, like social exchange theory, evolutionary theory predicts that people who maintain standards for a spouse that exceed their own desirability as a long-term mate will be left - at least temporarily - without a partner.

Marital search theory, adapted from job search theory by Oppenheimer (1988), offers a somewhat different framework for exploring the influence of individuals' spousal standards on their ease of partnering and marital behavior. Originally designed to address how difficulties finding a well-matched partner may affect marital timing, marital search 
theory maintains that people will settle on a mate only when the costs of continuing to search for a partner outweigh the anticipated benefits of doing so (e.g., finding a better matched spouse). These costs and benefits are presumed to depend on both a person's own value in the marriage market and the composition of potential mates he or she encounters (cf. Becker, 1981). In other words, people who have high mate value and meet many well-matched potential mates can be choosy and still find an acceptable partner reasonably quickly, whereas people who have lower mate value or are situated in less favorable mating pools will take longer to find a suitable partner unless they are less selective about who they are willing to accept. This suggests that people who hold mate criteria that are not well-calibrated to the likely costs and benefits of continued search will end up delaying their marital ambitions, sometimes indefinitely. Indeed, the longer individuals wait to marry, the more difficult and costly their search becomes, making it increasingly unlikely that they will secure a marriage partner without adjusting their standards (Lichter, 1990; Lichter, Anderson, \& Hayward, 1995). In sum, marital search theory complements and extends the social exchange and evolutionary perspectives by suggesting that holding standards for a spouse that overestimate the favorability of one's own mate value or the marriage market conditions one faces is likely to deter entry into marriage.

\section{EMPIRICAL Evidence: Do MATe Standards Really MATter?}

Despite theoretical consensus on the importance of holding realistic standards for successful partnering outcomes, empirical evidence for the link between mate standards and partnering behavior has been mixed. On the one hand, qualitative studies addressing unmarried individuals' reasons for delaying or forgoing marriage have generally supported the notion that the attainability of people's mate standards is connected to their 
marital behavior and decision-making. Much of this research has targeted disadvantaged parents who, despite asserting strong support for the institution of marriage, choose to remain single. For example, in a recent qualitative study of low-income, unmarried parents, Gibson-Davis and colleagues (2005) found that difficulties meeting one another's spousal expectations for financial stability and companionship were frequently cited as key barriers to marriage. This theme is also apparent in Edin and colleagues' (2000, 2005) work on low-income single mothers' beliefs about marriage; in these studies, many women reported that although getting married was a desirable goal, they would rather delay or forgo marriage than marry the financially insecure, unfaithful, and often abusive men who were available as partners. Although such minimum criteria for a spouse may not seem unreasonable, and most likely are advisable (e.g., Edin \& Kefalas, 2005), they are presumed to impede entry into marriage because they exceed the quality of marriage partner most low-income women are able to find and attract.

Interestingly, problematic discrepancies between what people want in a spouse and what they are able to get do not appear to be unique to individuals from underprivileged populations. Interviews with singles from middle-class samples indicate that - similar to their less advantaged counterparts - a majority of white, collegeeducated women who are never-married report that they are single because they have not yet found anyone who they were willing to marry (e.g., Dalton, 1992; Lewis \& Moon, 1997). In focus groups of never-married women ages 30-60, nearly all participants reported being very "choosy" in their search for a prospective spouse and many indicated becoming increasingly reluctant to "settle" as they grew older. "I would rather not be single," stated one middle-aged woman. "However, I am not willing to date or marry just anyone to avoid being single" (Lewis \& Moon, 1997, p. 125). Similar sentiments also were expressed by professional, never-married women in a more recent qualitative study 
by Sharp and Ganong (2007). Across these investigations, women commonly attributed their difficulty securing a good spouse to a combination of both personal deficits (e.g., being overweight, selfishness) and deficits on the part of the men they meet (e.g., immaturity, emotional inexpressiveness). Taken together, this qualitative work provides suggestive evidence that - at least in the eyes of never-married women - the tendency to delay or forgo marriage is closely tied to the inability to secure a partner who is up to par.

In contrast, the few quantitative investigations that have built upon this qualitative groundwork and explicitly tested the relation between mate standards and partnering behavior have generally produced null results. Indeed, recent social psychological work examining the influence of partner preferences on relationship initiation has suggested that there may be a fundamental disconnect between what people say they want or require in a partner and the way they actually behave (e.g., Eastwick, \& Finkel, 2008; Figuerdo, Sefcek, \& Jones, 2006). In one of the more notable of these studies, Eastwick and Finkel (2008) compared participants' previously reported mate preferences to their actual mate choices during a speed-dating event and found virtually no association between the attributes people said they wanted in a mate and the characteristics of the partners they selected. Other research using the speed-dating paradigm (see Finkel, Eastwick, \& Matthews, 2007, for an overview of this approach) has similarly shown that individuals' stated mate preferences or criteria tend to correlate poorly with their actual partnering decisions (Iyengar, Simonson, Fisman, \& Mogilner, 2005; Kurzban \& Weeden, 2007; Todd, Penke, Fasolo, \& Lenton, 2007). Although these studies focused exclusively on speed-dating and examined the influence of people's preferences on the types of partners they chose rather than their ability to successfully partner, they nevertheless call into question the presumed link between people's mate standards and their partnering behavior. 
Further complicating matters, the only two quantitative studies to directly examine the association between the stringency of people's spousal standards and their marital attitudes or behavior failed to find support for the expected link. In the first study, Raley and Bratter (2004) used data from two waves of the National Survey of Families and Households (NSFH) to test the hypothesis that people who are more willing to marry someone with less desirable attributes will be more likely to marry than those who hold more exacting criteria. Surprisingly, this prediction was largely unsupported. Despite marginal evidence that men with more flexible standards pertaining to physical attractiveness and the presence of children were more likely to marry, most of the effects for both men and women were nonsignificant and a few were even reversed. Women who were more willing to marry men who had been previously married or who were five years younger than themselves (traits that are generally not preferred) were actually less likely to marry than women who were more selective. More recent work by Bredow, Huston, and Glenn (2011) also failed to support the hypothesis that holding higher standards for a marriage partner is related to greater difficulty securing a spouse. In fact, the authors found that people who reported more demanding mate standards were actually more confident about their chances of securing a partner they would be willing to marry than those who reported being less choosy.

What might account for this surprising discrepancy between the theory and qualitative studies on mate standards and the existing quantitative work? At face value, the quantitative research described above may seem to argue that people's standards for a marriage partner are of little consequence to their later marital behaviors. But this is not necessarily the case. In addition to several plausible explanations for why people's preferences might not predict their behavior in speed-dating scenarios - including time constraints, limited information about potential partners, and the cognitive difficulties 
inherent in quickly evaluating prospects along multiple dimensions at once (e.g., Eastwick \& Finkel, 2008; Kurzban \& Weeden, 2007) - the counterintuitive findings of these studies might also be an artifact of the manner in which spousal standards were examined.

First, most research examining the influence of mate standards on partnering behavior has evaluated the "impact" of each mate preference independently, by testing, for example, whether holding higher standards for physical attractiveness encourages people to choose more physically attractive partners (e.g., Eastwick \& Finkel, 2008) or makes it more difficult to secure a partner to marry (e.g., Raley \& Bratter, 2004). However, given the complex trade-offs involved in partnering decisions (Li, Bailey, Kenrick, \& Linsenmeier, 2002) and the interactive effects of certain trait combinations on a partner's desirability (e.g., Jensen-Campbell, Graziano, \& West, 1995; Lundy, Tan, \& Cunningham, 1998), such individual effects may be exceedingly difficult to detect. People who generally hold high standards for educational attainment, for instance, may be willing to adjust this criterion if they meet a potential partner who compensates for this deficit by possessing other traits that they highly desire. Because people evaluate potential partners based on the package of attributes they possess, it may ultimately matter more that a potential spouse matches the overall quality of the mate one expects than that he or she measures up on any one particular trait (see Eastwick, Finkel, \& Eagly, 2011). As such, the link between spousal standards and marital behavior may be more apparent when mate criteria are examined as a set than when they are investigated individually.

Second, whereas both theory and qualitative work suggest that it is the attainability of people's standards that is important for their partnering outcomes, both Raley and Bratter (2004) and Bredow et al. (2011) operationalized mate standards in 
terms of absolute stringency rather than relative attainability. Although the authors included statistical controls for a handful of factors that influence the type of partner one is likely to secure (e.g., socioeconomic status, age, physical attractiveness), these controls were limited in scope and are unlikely to have captured the extent to which people's standards were truly realistic. Many people may set high standards for a spouse because such criteria are, in fact, fairly reasonable given their own mate value and the quality of the spouses available in their social milieus. To the extent that high standards tend to be more characteristic of singles who are in a better position to find and attract good partners, it is not surprising that the association between the absolute stringency of spousal standards and successful partnering outcomes would be inconsistent and sometimes positive. Indeed, past work on relational standards has frequently shown that holding more stringent standards - in and of itself - is associated with better rather than poorer relationship outcomes (e.g., Baucom, Epstein, Rankin, \& Burnett, 1996; Fletcher et al., 1999; Morrow \& O’Sullivan, 1998; Murray, Griffin, \& Holmes, 1996). By developing a model to more directly quantify the attainability of individuals' standards for a spouse, this research seeks to estimate more accurately the implications of spousal criteria for later marital behavior.

\section{OVERVIEW OF THE CURRENT INVESTIGATION}

The current investigation is designed to fill in gaps in the literature on mate standards and partnering by examining whether holding unrealistic standards for a marriage partner - as assessed by the model in Figure 1 - is associated with partnering difficulties and other indicators of a propensity to delay or forgo marriage. Defining an individual's mate criteria as more or less realistic requires a benchmark - a measure of what is attainable - against which his or her standards can be compared. As described in 
the previous sections, both theory and qualitative work (e.g., Edin, 2005; Lewis \& Moon, 1997) suggest that individuals' criteria for a spouse are "realistic" to the extent that they reflect both their own overall desirability as a long-term partner and their access to desirable prospective mates. Although numerous studies have shown that, on average, people's spousal standards are positively associated with their mate value and with the availability of high-quality partners (e.g., Bredow et al., 2011; Kenrick et al., 1993; Sprecher \& Regan, 2002), there is often considerable variation in the extent to which individuals' reported standards reflect their mating constraints (Bredow \& Huston, 2009; Pawlowski \& Dunbar, 1999). Whereas some people's standards closely approximate their opportunity structure, others' criteria are notably higher than would be expected given their social desirability and partnering context. Based on these principles, the model used in the present research operationalizes unrealistic spousal standards as people's tendency to hold minimum criteria for a marriage partner that are more stringent than would be expected based on their own mate value, the composition of their marriage market, and the interaction between the two.

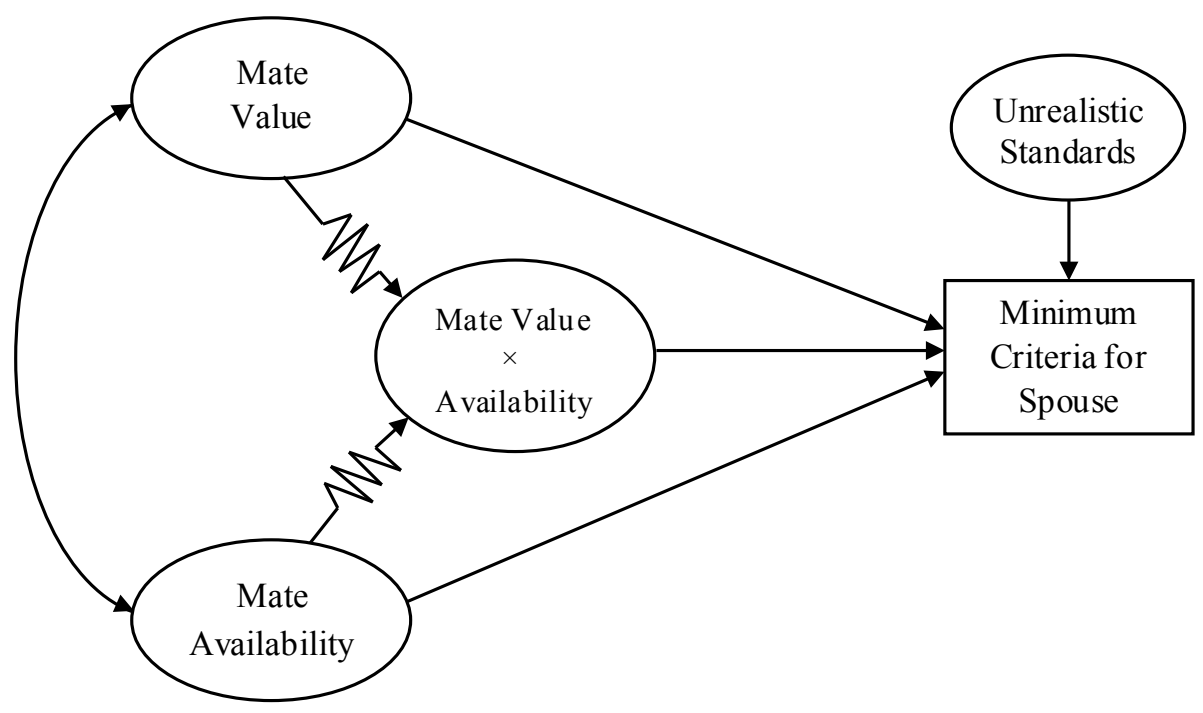

Figure 1. Conceptual model for assessing unrealistic standards for a marriage partner. 
Rather than relying on a single, self-report measure to estimate people's mate value or access to desirable partners (as has been done in the past), mate value and mate availability are represented in the model in Figure 1 as latent constructs whose values are inferred on the basis of multiple indicators of people's spousal desirability and marriage market conditions. Importantly, in order to take advantage of the greater reliability and accuracy afforded by combining the unique reports of multiple informants (e.g., Kolar, Funder, \& Colvin, 1996; Vazire, 2006), each indicator is created from both self- and peer-reported information (i.e., reports provided by a friend or relative). By reducing measurement error in the variables, using a multi-informant, multi-indicator approach to assess people's mate value and the favorability of their marriage markets allows me to best capture the "reality" of people's opportunity structures - and thus the type of partner they are likely to secure. Based on past research suggesting that singles' mate value and mating market quality are generally interrelated (Bredow et al., 2011), these two constructs are presumed to be correlated in the model. A latent interaction term (i.e., Mate Value $\times$ Mate Availability) is also included to assess the possibility that the strength of the association between people's own desirability as a marriage partner and the stringency of their mate standards may depend upon the availability of desirable potential partners (and vice versa). Indeed, we would expect the positive association between individuals' mate value and their spousal standards to be stronger in situations where mate availability is high (allowing desirable individuals to have their pick of similarly desirable partners) than when mate availability is low (making partners of comparable desirability difficult to find).

In sum, the present study considers an individual's standards to be less realistic to the extent that they are higher than what is predicted based on his or her own mate value, the availability of desirable partners, and the interaction between the two variables. 
Specifically, unrealistic spousal standards are assessed using residual scores (represented by the oval labeled "Unrealistic Standards" in Figure 1), where more positive residuals reflect standards for a marriage partner that are less realistic relative to others in the sample. This approach has a counterpart in the literatures on self-enhancement bias and positive illusions, and has been successfully used in past research to quantify unrealistically positive self and partner assessments (e.g., Barelds \& Dijkstra, 2011; John \& Robins, 1994; Miller, Niehuis, \& Huston, 2006; Paulhaus, 1998; Robins \& Beer, 2001). ${ }^{1}$

The residual scores produced by the model in Figure 1 will constitute the basis for subsequent analyses of the association between the attainability of people's spousal standards and their partnering outcomes. Although it is ultimately of interest to assess whether people who hold less realistic criteria for a marriage partner are actually less likely to marry than their more "pragmatic" counterparts, an important first step is to examine potential intermediaries in this process. That is, if the attainability of spousal standards is likely to affect people's future marital behavior, we would expect unrealistic mate criteria to be associated concurrently with attitudes and behaviors that are indicative of partnering difficulties and that predict lower rates of entry into marriage. One way that partnering difficulties might be manifested in singles is in lower dating and relationship success. Individuals who maintain mate standards that are not realistic may experience persistent difficulties initiating and maintaining romantic relationships because the partners available to them will generally fail to meet their expectations. These

\footnotetext{
${ }^{1}$ See Overall, Fletcher, and Simpson (2006) and Knee, Nanayakkara, Vietor, Neighbors, and Patrick (2001) for additional examples of utilizing residualized indices in relationship research.

${ }^{2}$ Only 12 participants $(2.4 \%)$ indicated that they were definitely not interested in getting (re)married someday and analyses excluding these individuals produced results that were virtually identical to those using the entire sample; thus, the full sample of 502 individuals was retained.

${ }^{3}$ Despite asking participants not to nominate parents $\mathrm{P} 2$ current romantic partners as informants, a small number of the responding informants self-identified as either a parent $(\mathrm{N}=35)$ or a current dating partner $(\mathrm{N}=21)$. A series of independent sample $\mathrm{t}$-tests revealed that although parents rated target participants
} 
individuals may have greater difficulty establishing committed romances, experience shorter-lived relationships, and be less satisfied with their past and present dating experiences. Moreover, because people with less attainable spousal standards may have to settle for "subpar" partners in order to form romantic relationships, we would expect the relationships they do establish to be lower in quality than those of individuals with more realistic criteria. Such a finding would be consistent with a substantial body of work suggesting that larger disparities between people's desired partners and their views of their actual partners are associated with lower relationship satisfaction and higher rates of dissolution (e.g., Campbell, Simpson, Kashy, \& Fletcher, 2001; Fletcher, Simpson, \& Thomas, 2000; Zenter, 2005). Accordingly, the following the two hypotheses were tested:

H1: Individuals who hold less realistic standards for a marriage partner will report lower dating success than those who hold more realistic standards.

H2: Partnered individuals who hold less realistic standards for a marriage partner will have lower quality romantic relationships than those who hold more realistic standards.

An accumulation of negative dating and relationship experiences, in turn, may lead individuals with less realistic standards to adopt attitudes and behaviors that are associated with a lower likelihood of marriage, including lower expectations to marry and decreased investment in finding a marriage partner. Prior research suggests that when people's "attainable mate" does not meet their standards for an "acceptable mate", they are less likely to believe that they will get married, both with respect to their current partner (e.g., Waller \& McLanahan, 2005) and in general (Bredow et al., 2011). Given that individuals' expectations to marry tend to be reliable precursors of their actual entry into marriage (e.g., Brown, 2000; Lichter et al., 1992; Smock \& Manning, 1995; Waller 
\& McLanahan, 2005), we would expect people with less realistic criteria to view their prospects of marriage less favorably if their standards are likely to deter future marital behavior. Moreover, to the extent that pervasive partnering difficulties lead to bleak marital forecasts, people with less attainable standards may cope with their unpromising circumstances by disengaging - both psychologically and behaviorally -from the pursuit of marriage as a valued goal (e.g., Bredow et al., 2011; Wrosch, Scheier, Miller, Schultz, \& Carver, 2003). Indeed, evidence suggests that withdrawing from goals that are unattainable is common and psychologically adaptive (Carver \& Scheier, 1998; Weiner, 1992; Wrosch et al., 2003). Thus, in order to mitigate the impact of repeated partnering failures on their subjective well-being, individuals who hold less realistic standards may view marriage as less desirable and invest less time and effort pursuing it than those with more attainable criteria.

Notably, because the aforementioned processes are likely to unfold over time, we might expect the effects of holding less attainable standards on expectations to marry and investment in marrying to be more pronounced in individuals who are older or who have more relationship experience. Past work suggests that younger individuals are more prone to hold unrealistic or romanticized views of marriage than their older counterparts, perhaps, in part, because they have fewer relationship experiences to use as a basis for "reality" (e.g., Cobb, Larson, \& Watson, 2003; Sharp \& Ganong, 2000). Among young, college-aged individuals, for instance, unrealistically high spousal standards may reflect a general propensity to view marriage through rose-colored glasses (e.g., Segrin \& Nabi, 2002). Because such singles have yet to accumulate much evidence about the attainability of their standards, they may be able to maintain unrealistic spousal criteria and still feel fairly optimistic about their likelihood of securing an acceptable partner to marry. However, as people accrue relationship experience and gain a better appreciation 
for the mating market and its dynamics, we would expect those who maintain unattainable mate criteria to be increasingly likely to see their goal of marrying as out of reach (cf. Heckhausen \& Schultz, 1995). Accordingly, I hypothesized that:

H3a: Individuals who hold less realistic standards will express lower expectations to marry than those who hold more realistic standards.

$\mathrm{H} 3 \mathrm{~b}$ : The association between maintaining realistic spousal standards and expectations to marry will be stronger for individuals who are older and have more relationship experience than for those who are younger and have less relationship experience.

H4a: Individuals who hold less realistic standards for a marriage partner will be less psychologically and behaviorally invested in marrying than individuals who hold more realistic standards.

H4b: The association between maintaining realistic spousal standards and investment in marrying will be stronger for individuals who are older and have more relationship experience than for those who are younger and have less relationship experience. 


\section{Chapter Two: Method}

\section{Participants}

Unmarried individuals aged 18 and older were recruited from a variety of settings, including social science courses at a large, public U.S. university, evening classes at a local community college, the mailing lists of several community and professional organizations, and Internet marketplace and social media sites (e.g., Amazon Mechanical Turk, Craigslist, Facebook). In total, 767 heterosexual individuals completed the survey over a 3-month period. Complete data was collected for about two-thirds of these participants (i.e., self-reports plus at least one informant response), yielding a sample of 502 unmarried individuals (144 men, 358 women) for the present study. ${ }^{2}$ These participants ranged in age from 18 to 79 , with a mean age of $29.30(S D=11.16)$. Three hundred and forty eight $(69.3 \%)$ of the participants were non-Hispanic White, 70 were Hispanic (13.9\%), 41 were Asian American (8.2\%), 23 were African American (4.6\%), and the remainder identified themselves as Native American, Middle Eastern, or mixed ethnicity $(\mathrm{N}=20,4 \%)$. Approximately half of the participants were full- or part-time students (37.5\% and $12.4 \%$, respectively) and most $(81.1 \%)$ of the non-student participants held a Bachelor's degree or higher. A majority of the sample was never married $(81.5 \%)$, and $47.4 \%$ of the participants were currently involved in a romantic relationship.

\section{Procedure}

After providing informed consent, respondents completed an online questionnaire assessing, among other things, their personal qualities, marital attitudes, and dating

\footnotetext{
${ }^{2}$ Only 12 participants (2.4\%) indicated that they were definitely not interested in getting (re)married someday and analyses excluding these individuals produced results that were virtually identical to those using the entire sample; thus, the full sample of 502 individuals was retained.
} 
experiences. At the end of the questionnaire, participants were directed to a nomination form which asked them to provide the first name and email addresses of three friends or relatives who know them well and might be willing to answer a brief set of questions about the participant. Individuals were instructed to nominate at least one informant of each sex if possible, and to avoid nominating their parents or current romantic partners (who tend to be overly positive in their assessments). Also, to maximize the likelihood that the nominated informants would have first-hand exposure to participants' marriage market conditions, individuals were asked to list peers who they regularly interacted with in person. Participants were assured that the informants' ratings would be kept completely confidential and that they would never see their peers' responses or vice versa. On average, the entire process took about 20-25 minutes to complete. As compensation, participants were either (a) provided a small amount of extra credit in a university course, (b) entered into a raffle for one of fifteen $\$ 40.00$ amazon.com gift cards, or (c) paid a small monetary award (i.e., $\$ 1.00$; for those recruited through MTurk). To eliminate any possible motivation for participants to provide fake peer reports, participants' compensation was not contingent on the informants' cooperation.

Following Vazire (2006), the nominated peers were contacted by email within the next few days and asked to complete a short online questionnaire about the target participant. After clicking the unique hyperlink provided in the email, informants were brought to a questionnaire consisting mostly of questions about the personal attributes and marriage market conditions of the friend or relative who nominated them. Altogether, the survey took about 5-10 minutes to complete. Informants who did not complete the questionnaire were sent up to three reminder emails at two week intervals. To increase response rates, nominated peers were entered into a drawing to receive one of ten $\$ 25$ gift cards in return for completing the survey (participants were not aware of this 
incentive when nominating their informants; thus the integrity of the peer nomination process was not compromised).

Of the 767 target participants who completed the survey, $619(80.7 \%)$ provided at least one valid peer nomination and $493(64.3 \%)$ provided all three requested nominations. Altogether, participants nominated a total of 1573 potential informants. Two months after the end of the study, 993 informants had completed the survey $(63.1 \%$ response rate), most of whom self-identified as friends (64.7\%), siblings (14.8\%), or other relatives (9\%; e.g., cousin, aunt). ${ }^{3}$ At least one informant response was obtained for 502 of the 767 respondents; of these 502 participants, a single peer response was obtained for 177 individuals (35.3\%), two peer responses were obtained for 160 individuals (31.9\%), and three peer responses were obtained for 165 individuals (32.9\%). Importantly, participants with one or more informant responses (i.e., those included in the present study) did not significantly differ from participants with no informant responses on any of the demographic or analytic variables examined in this study. In order to take advantage of the greater reliability and predictive validity gained by using aggregated informant reports (e.g., Kenny, 2004; Kolar et al., 1996; Vazire, 2010; Vazire \& Mehl, 2008), multiple peer ratings of the same participant were aggregated to form a single, composite peer-rating when applicable. ${ }^{4}$ Consistent with past research (e.g., Kenny,

\footnotetext{
${ }^{3}$ Despite asking participants not to nominate parents or current romantic partners as informants, a small number of the responding informants self-identified as either a parent $(\mathrm{N}=35)$ or a current dating partner $(\mathrm{N}=21)$. A series of independent sample $\mathrm{t}$-tests revealed that although parents rated target participants significantly higher than non-parents on a few of the variables (e.g., relative mate value, global mate availability), these differences were small in absolute magnitude. There were no significant mean differences between the ratings provided by partners and non-partners on any of the mate value or mate availability variables. As a result, I decided to retain these 56 informants in my analyses.

${ }^{4}$ Although this approach produces peer indices that differ in reliability based on the number of peer reports obtained, this is primarily problematic in situations where the predictive validity of various raters' reports are being compared (see Vazire, 2010; Vazire \& Mehl, 2008). In the present study, my goal is to calculate unrealistic standards as accurately as possible by drawing on multiple perspectives; thus it makes sense to use all available data to capture the "reality" of people's opportunity structures.
} 
2004), there was a moderate level of agreement between informants on the various indices, with an average pairwise informant agreement correlation of .30 .

\section{MeASURES}

Minimum standards for a marriage partner. Participants' minimum standards for a marriage partner were assessed using a set of 18 characteristics adapted from previous research on the attributes that people commonly seek in a long-term mate (e.g., Bredow et al., 2011; Buss et al., 2001; Edin, 2000; Fletcher et al., 1999). These attributes were presented in a random order and included kind and understanding, well-educated, healthy and fit body, good sense of humor, intelligent, outgoing and sociable, honest and trustworthy, ambitious and hard-working, warm and emotionally expressive, adventurous and fun personality, financially stable/good financial prospects, sober and drug-free, good-looking and sexy, dependable, unselfish, has well-paying job/good career prospects, sexually faithful, and emotionally stable (see Appendix A). For each characteristic, participants were asked to indicate on a scale from 0 (not at all) to 10 (extremely) the minimum level of the characteristic a person would need to have to be considered an acceptable marriage partner. To clarify the response scale, an example was provided (e.g., "A score of 0 would indicate that a person does not need to be at all intelligent, a score of 5 would indicate that a person must be somewhat intelligent, and a score of 10 would indicate that a person must be extremely intelligent"). Responses to the 18 items were averaged to yield an index of the overall stringency of people's criteria for a marriage partner (Cronbach's $\alpha=.88$ ).

Mate value. Participants' overall desirability as a long-term mate was assessed using both self- and peer-ratings of (a) the extent to which the participant possesses specific attributes that are desirable in a spouse, (b) the participant's global desirability as 
a spouse, and (c) the participant's relative desirability as a spouse. Self- and peer-reports of participants' attributes were measured using a procedure parallel to that used to assess minimum standards for a marriage partner. For each of the 18 characteristics listed in the preceding section, participants were asked to indicate on a scale from 0 (not at all) to 10 (extremely) the extent to which they possess the characteristic in question. "Outside" reports of people's mating-relevant attributes were assessed by asking peer informants to describe the participants on the same 18 qualities, using an identical scale. As with mate standards, an example of the response scale was provided. Scores on the 18 items were averaged to create separate self- and peer-reported attribute-based indices of participants' overall mate value (Cronbach's $\alpha$ s $=.84$ and .88 , respectively).

Participants' global evaluations of their own mate value were measured using two items adapted from past research (Huston, 2001) or written for the present study. For the first item, participants were instructed to think about the qualities that most people consider desirable in a spouse and to rate their own current desirability as a marriage partner on a scale from 1 (I'd make a bad marriage partner) to 10 (I'd be a great catch). On the second item, participants used a 7-point scale to indicate the extent to which they agreed or disagreed with the statement "Once they got to know me, most men/women would consider me to be a desirable partner in a long-term relationship." Parallel items with slightly modified wording were used to assess peers' global perceptions of participants' mate value. After being standardized, responses to the two items were averaged to form self- and peer-reported global mate value composites (Cronbach's $\alpha \mathrm{s}=$ .67 and .73 , respectively).

Finally, participants' relative mate value was assessed using two items written for the present study. In the first item, participants were instructed to think about the qualities that people generally want in a spouse and to indicate their desirability as a marriage 
partner relative to other same-sex individuals $(1=$ much less desirable, $7=$ much more desirable). Participants also indicated the extent to which they agreed or disagreed with the statement "I have more to offer as a romantic partner than most men/women my age" $(1=$ strongly disagree, $7=$ strongly agree $)$. Two parallel items were used to measure peer-reported relative desirability. As with the global ratings, responses to the two items were averaged to create self- and peer-reported indices of participants' relative mate value (Cronbach's $\alpha$ s $=.69$ and .77 , respectively). A complete list of the mate value items composing each measure is provided in Appendix B.

Mate availability. Based on the notion that both the quantity and the quality of potential partners in people's social milieus matters (see Bredow et al., 2011), mate availability was assessed using self- and peer-reports of (a) the extent to which potential partners possess attributes that are generally desired in a spouse, and (b) the global availability of eligible singles who could make acceptable marriage partners. With respect to the former, participants were asked to indicate the extent to which the eligible, opposite-sex people they typically encounter possess each of the aforementioned 18 attributes (e.g., "Most of single men/women I encounter are intelligent"). Informants' evaluations of the attributes of the potential partners in their peer's market were assessed using a parallel procedure (e.g., "Most of the single men/women [participant name] encounters are intelligent"). Agreement with each item was indicated on a 7-point scale $(1=$ strongly disagree, $7=$ strongly agree $)$ and scores were averaged to create self- and peer-reported measures of the overall desirability of the potential partners in the target participants' marriage markets (Cronbach's $\alpha \mathrm{s}=.90$ and .94 ). To account for the fact that meeting potential partners with desirable qualities does little to improve one's marital prospects if these individuals are not interested in marrying, participants and their informants also completed a single item measure indicating the extent to which they 
perceived available singles as open to getting married (e.g., "Most of the single men/women I meet are interested in making a commitment and getting married").

Participants' global evaluations of the availability of potential marriage partners were assessed using seven items modified from past research (Sprecher \& Regan, 2002) or written for the present study. For the first five items, participants rated their agreement with a number of statements concerning their perceptions of the overall availability of potential partners (e.g., "I rarely encounter desirable men/women who are available for a long-term relationship"; 1 = strongly disagree, 7 = strongly agree). Individuals also used a 7-point scale to estimate the general availability of eligible singles who would make good marriage partners $(1=$ very few available, $7=$ more than enough available $)$ as well as the number of single men/women around their age they encounter in their day-to-day lives $(1=I$ never meet any single/men my age, 7 = I meet a ton of single men/women my age). Seven parallel items were used to assess peers' global evaluations of the target participants' mating pools. Exploratory factor analyses with oblique rotations revealed that all but one of the seven items loaded strongly on a single factor. These six items were averaged to create self- and peer-reported indices of global mate availability (Cronbach's $\alpha s=.76$ and .77). Self- and peer-reports on the remaining item, which taps more into the global quality of available partners than the global availability of partners, were retained as single-item measures (e.g., "Most of the single men/women I meet have the qualities people generally look for in a spouse"). A complete list of the mate availability items is available in Appendix C. Notably, because estimating mate value and the availability of desirable mates might influence people's reports of their spousal standards (and vice versa), these three measures were counterbalanced in the questionnaire. 
Dating success. To capture the range of ways the attainability of people's standards may influence their dating experiences, four potentially distinct domains of dating success were assessed, including number of involvements, duration of involvements, perceived quality of past relationships, and dating satisfaction. The items, which were adapted from Urbaniak and Kilmann's (2006) Dating History Questionnaire (DHQ) or written for the present study, were selected based on theoretical considerations of various types of "success" within the context of establishing committed romantic relationships.

Participants' number of committed relationships was assessed by asking individuals to report the total number of exclusive/committed romantic relationships they have been involved in over the course of their lifetime. Participants also reported on the duration of their committed relationships, indicating the average length of time they spent in each relationship ( $1=$ Less than 6 months, $7=$ Over five years $)$ and the length of their longest exclusive/committed relationship $(1=$ Less than 6 months, $12=$ More than 10 years). Scores on the two duration items were standardized and averaged to create an overall index of the duration of individuals' committed romantic relationships (Cronbach's $\alpha=.86$ ).

Individuals' perception of the overall quality of their past relationships was assessed using three items. Specifically, participants who had been involved in at least one committed relationship (prior to their present relationship, if romantically involved) were asked to specify how satisfying their past exclusive/committed romantic relationships had been compared to most people's relationships ( 1 = much less satisfying, $7=$ much more satisfying) and to indicate their agreement with two statements pertaining to the quality of their past relationships (e.g., "Most of my past relationships have been a disappointment;" 1 = strongly disagree, 7 = strongly agree ). After reverse scoring the 
negatively worded items, responses to the three items were averaged to create a measure of past relationship quality (Cronbach's $\alpha=73$ ). Lastly, participants' general dating satisfaction was measured by asking individuals to indicate, using a 7-point scale, the extent to which they agreed or disagreed with the statement "I am satisfied with the current state of my love life" $(1=$ strongly disagree, $7=$ strongly agree $)$. A complete list of the items composing each of the dating success measures is provided in Appendix D.

Relationship quality. The perceived quality of individuals' romantic relationships was assessed using three constructs that may be particularly influenced by people's inability to secure partners who live up to their standards: relationship satisfaction, dedication to the relationship, and relational ambivalence. Relationship satisfaction was measured using Murray, Holmes, Dolderman, and Griffin's (2000) fouritem index, which assesses individuals' global evaluations of their relationships (e.g., "I am extremely happy with my current romantic relationship”). Participants responded to each item on a 9-point scale $(1=$ not at all true, $9=$ extremely true $)$. Individuals' dedication to their relationship was assessed using the six-item relationship agenda subscale from Stanley and Markman's (1992) Commitment Inventory. These items, which tap into people's personal dedication to maintaining their relationships, asked participants to indicate the extent to which they desire to see their relationships continue over time (e.g., "I want to grow old with [partner name];" $1=$ strongly disagree, $7=$ strongly agree). Finally, relationship ambivalence - defined as the extent to which individuals feel conflicted about their involvement with their partner - was assessed using four items adapted from Braiker and Kelley’s (1979) ambivalence scale, as well as two items written by the main author (e.g., "I feel somewhat confused about my feelings toward [partner name]"). Each item was answered on a 7-point scale, ranging from 1 (strongly disagree) to 7 (strongly agree). After reverse-scoring the negatively worded 
items, participants' scores were averaged within each scale to create measures of relationship satisfaction $(\alpha=.93)$, relationship dedication $(\alpha=.94)$, and relationship ambivalence $(\alpha=80)$. See Appendix E for a list of the items included in each scale.

Expectations to marry. To assess general expectations to someday marry, participants were asked to rate their chances of eventually (re)marrying on a scale from 0 (no chance) to 10 (100\% chance) and to indicate their agreement with the item "I am positive that I will get (re)married someday" ( 1 = strongly disagree, $7=$ strongly agree $)$. Responses to these two questions were standardized and combined to form a single scale (Cronbach's $\alpha=.89$ ). Participants who were involved in a romantic relationship also were asked to estimate the likelihood that they would marry their current partner $(0=n o$ chance, $10=100 \%$ chance) and to indicate their agreement with the statement "There is no doubt in my mind that [partner name] and I will get married someday" $(1=$ strongly disagree, 7 = strongly agree). As with general expectations, these two items were standardized and averaged to create an overall index of individuals' expectations to marry their current partner (Cronbach's $\alpha=.91$; see Appendix F).

Investment in marrying. Following Wrosch and colleagues' (2003) suggestion that disengaging from an unattainable goal requires reframing the goal as less important as well as devoting less energy to its pursuit, both psychological and behavioral investment in marrying were assessed. To measure individuals' psychological investment in marrying, participants who were not formally engaged were asked to indicate their agreement with four items that were adapted from Blakemore, Lawton, and Vartanian's (2005) Drive to Marry scale (e.g., "I can't wait to get married;" "I will be extremely disappointed if I never get (re)married"). Participants also indicated the extent to which they endorsed four marital attitudes that prior research has linked to people's likelihood of marrying, such as "It is better to be married than to go through life being single" and 
"My life would be more fulfilling if I were married" (e.g., Axinn \& Thornton, 1992; Carlson, McLanahan, \& England, 2004; Clarkberg, Stolzenberg, \& Waite, 1995; Sassler \& Schoen, 1999). All eight items were rated on a 7-point scale ranging from 1 (strongly disagree) to 7 (strongly agree). After reverse-scoring the two negatively worded questions, responses to the eight items were averaged to create an overall index of the importance participants attached to getting married, where higher scores reflect greater psychological investment in marrying (Cronbach's $\alpha=.90$ ). To explore whether diminished investment in marrying might also be apparent in individuals' interest in pursuing relationships more generally, participants who were currently single were also asked to rate their agreement with the statement "I am not interested in dating at this point in time". For ease of interpretation, responses to this question were reverse-scored to create a single-item measure where higher scores indicate greater interest in dating.

Behavioral investment in marrying was measured by assessing individuals' subjective impressions of the effort they put into finding a partner to marry, as well as their reports of how often they engage in behaviors that are indicative of such efforts. First, participants who were casually dating or not involved in a romantic relationship were asked to rate their agreement with two statements regarding their current investment in the mating market (e.g., "I am actively looking for a partner who would make a good spouse;" 1 = strongly disagree, 7 = strongly agree $)$. Second, these individuals were asked to identify which (if any) of the following methods they used in the past year to try to meet potential romantic partners: (a) engaged in co-ed leisure activities, (b) participated in organized social groups, (c) went speed-dating, (d) used a free Internet dating service, (e) used a paid Internet dating service, (f) had a friend set them up with someone (i.e., a "blind date"), or (g) visited bars or clubs. For each method individuals reported having used, they also indicated how frequently they engaged in that activity (1 
$=I$ did this once, $7=I$ did this a lot). Responses to these questions were used to create two variables: one reflecting the number of different methods participants reported using in the past year (sum of the methods checked; possible scores ranged from 0-7) and one reflecting how frequently participants engaged in these various methods (sum of the frequency scores; possible scores ranged from 0-49). These four items were standardized and averaged to create an index of participants' behavioral investment in securing a partner to marry (Cronbach's $\alpha=.80$ ).

Lastly, to examine the possibility that lower investment might also be apparent in the number of dates an individual actually initiates or accepts, participants who were not currently involved in a romantic relationship were asked to indicate, as best as they could remember, how many dates they had been on in the past year. After removing two individuals with extreme, outlying responses (e.g., 500 dates), responses to this item were used as a single-item measure of dating behavior. ${ }^{5}$ A complete list of the items included in each scale is included in Appendix G.

Control variables. To account for dispositional factors that may influence the strength of the association between the attainability of people's standards and their reported partnering outcomes, participants' global positivity, self-esteem, and attachment anxiety were included as controls in all regression analyses. Global positivity was measured using the revised Life Orientation Test (LOT-R; Scheier, Carver, \& Bridges, 1994), a six-item measure designed to assess people's generalized expectancies for positive versus negative outcomes. Using a 5-point scale, participants indicated the

\footnotetext{
${ }^{5}$ Although the number of dates a person reports could also be thought of as an indicator of their dating success, a low number of dates is not necessarily indicative of "low success" in situations where people are not actually pursuing a relationship. Accordingly, I decided to classify number of dates as an indicator of behavioral investment; that is, people who are less invested in marrying may also be less invested in trying to find a romantic partner at all. However, readers should be mindful of the conceptual overlap between this variable and dating success when interpreting the results.
} 
extent to which they agreed with statements such as "In uncertain times, I usually expect the best" ( 1 = strongly disagree, 5 = strongly agree $)$. Self-esteem was measured using Rosenberg's (1965) 10-item scale, which captures people's sense of global self-worth using items such as "On the whole, I am satisfied with myself." Participants rated their agreement with each item on a scale from 1 (strongly disagree) to 5 (strongly agree). Finally, individuals' attachment anxiety was assessed using the short form of the Experiences in Close Relationships Scale (ECR; Wei, Russell, Mallinckrodt, \& Vogel, 2007). On a 7-point scale, participants indicated the extent to which they agreed with six statements about the ways they relate to romantic partners (e.g., "I worry that romantic partners won't care about me as much as I care about them;" $1=$ strongly disagree, $7=$ strongly agree). After reverse scoring the negatively worded items, item scores were averaged within each scale to yield measures of general positivity $(\alpha=.84)$, global selfesteem $(\alpha=.90)$, and attachment anxiety $(\alpha=.79)$.

In addition to the aforementioned measures, a number of demographic and background variables also were included as covariates. Based on evidence that men and women may differ in their propensity to hold unrealistic standards and in their attitudes toward marriage (e.g., Blakemore et al., 2005; Bredow \& Huston, 2009), gender was added as a control in all regression analyses. Given that factors such as age, ethnicity, previous marital experience, and involvement in a romantic relationship also have been shown to be associated with many of the outcome variables (e.g., number of committed relationships, expectations to marry; Bredow et al., 2011), these variables also were controlled. Lastly, because preliminary analyses revealed that both the salience and flexibility of people's standards were related to a number of the outcomes, these potential confounds were included as additional controls. The salience of individuals' mate standards was assessed using four items written by the author (e.g., "I have given a lot of 
thought to the qualities I want in a marriage partner"). Participants rated their agreement with each item on a 7 point scale $(1=$ strongly disagree, $7=$ strongly agree $)$ and the scores from these items were averaged to create a mate standard salience index (Cronbach's $\alpha=.76$ ). The flexibility of people's reported standards was measured with a single item: "If I loved someone, I would be willing to marry him/her even if he/she did not meet some of my criteria for a marriage partner" $(1=$ strongly disagree, $7=$ strongly agree). A list of the specific items composing each covariate measure is provided in Appendix H.

\section{AnAlytic Strategy}

Data analyses were conducted in two steps. First, to calculate unrealistic standards, the model in Figure 1 was estimated using structural equation modeling (SEM) in LISREL 8.80 (Jöreskog \& Sörbom, 1999). Given the very small amount of missing data in my sample (less than $2 \%$ missing on any variable), maximum likelihood (ML) estimation was used to handle the missing data points (Allison, 2003; Schafer \& Graham, 2002). Individuals' minimum standards for a marriage partner were presumed to be a function of two exogenous latent variables - mate value and mate availability - and the interaction between these variables. To create the indicators for the latent factors, I averaged the corresponding self- and peer-reported measures of each construct to create a total of seven observed indicators - three associated with mate value (i.e., an attributebased measure, a global measure, and a relative measure) and four associated with mate availability (i.e., an attribute-based measure, a commitment measure, a global quantity measure, and a global quality measure). Consistent with past research demonstrating the benefits of giving similar weight to self- and peer-ratings when attempting to predict people's behavior (e.g., Vazire \& Mehl, 2008), the selected approach performed better 
than alternative approaches in terms of indicator reliability, model fit, and predictive ability. ${ }^{6}$ Descriptive statistics for and correlations between the self- and informantratings on each measure are provided in Table 1.

Table 1. Descriptive Statistics for Self- and Informant-Ratings of Mate Value and Mate Availability

\begin{tabular}{|c|c|c|c|c|c|c|}
\hline & \multicolumn{2}{|c|}{ Self-rating } & \multicolumn{2}{|c|}{ Informant rating } & \multirow{2}{*}{$\begin{array}{l}\text { Paired- } \\
\text { sample } t\end{array}$} & \multirow{2}{*}{$\begin{array}{c}\text { Self- } \\
\text { informant } r\end{array}$} \\
\hline & $M$ & $S D$ & $M$ & $S D$ & & \\
\hline \multicolumn{7}{|l|}{ Mate Value } \\
\hline Attributes & 7.85 & 0.93 & 8.12 & 1.04 & $-5.09 * * *$ & $.29 * * *$ \\
\hline Global & 0.00 & 0.84 & -0.00 & 0.89 & 0.06 & $.25 * * *$ \\
\hline Relative & -0.00 & 0.06 & 0.00 & 0.90 & -0.02 & $.15^{* *}$ \\
\hline \multicolumn{7}{|l|}{ Mate Availability } \\
\hline Attributes & 4.79 & 0.77 & 4.83 & 0.81 & -1.08 & $.21 * * *$ \\
\hline Commitment & 3.76 & 1.61 & 4.20 & 1.26 & $-5.89 * * *$ & $.26 * * *$ \\
\hline Global Quantity & 3.70 & 1.12 & 4.01 & 1.04 & $-6.02 * * *$ & $.46^{* * *}$ \\
\hline Global Quality & 3.89 & 1.33 & 4.30 & 1.12 & $-5.75 * * *$ & $.13 * *$ \\
\hline
\end{tabular}

$* * p<.01 .{ }^{* * *} p<.001$.

Following Marsh, Wen and Hau (2004), I used an unconstrained approach to estimate the effect of the latent interaction between mate value and mate availability on standards for a marriage partner. In addition to being much less cumbersome than traditional "constrained" approaches (which use complex nonlinear constraints to define the relations between the cross-product indicators and the latent interaction variable; e.g., Kenny \& Judd, 1984), the unconstrained modeling approach has the advantage of being more robust with respect to violations in the assumption of multivariate normality (Marsh

\footnotetext{
${ }^{6}$ Due to the relatively low levels of shared variance typically found between self-ratings of personal attributes and the ratings of knowledgeable informants (e.g., Kenny, 2004), constructing the model using separate (unaveraged) self- and peer-reported indicators for each measure demonstrated a considerably worse fit to the data than the averaged-indicator model. Moreover, the residuals produced using nonaveraged models were notably worse predictors of partnering outcomes than those produced using the averaged approach (likely because the common variance extracted in the separate-indicator models tended to overweight self-reports of mate value and mate availability).
} 
et al., 2004). To create the mate value $\times$ mate availability interaction variable, I mean centered the indicators of the component latent variables and used a matched-pair strategy to construct cross-products of the indicators (using all three mate value indicators and three of the four mate availability indicators). Thus, three cross-product pairs (e.g., attribute-based mate value $\times$ attribute-based mate availability) were used as indicators of the latent interaction construct. Because incorporating a latent interaction term into the model yields an improper standardized solution, all variables were $\mathrm{z}$-standardized prior to the analyses. Furthermore, the latent variances were fixed at 1 to allow straightforward interpretation of the relations within the structural model.

As recommended by a number of authors (e.g., Hu and Bentler, 1999; McDonald \& Ho, 2002), a combination of several criteria were used to evaluate the goodness-of-fit of the model, including the root mean square error of approximation (RMSEA), the comparative fit index (CFI), and the standardized root mean square residual (SRMR). CFI values of at least .90 indicate an adequate fit, and values of .95 or higher indicate a strong fit (Kline, 2005); RMSEA and SRMR values of .05 reflect a close fit to the data, with values up to .08 considered acceptable (Brown \& Cudeck, 1993; Hu \& Bentler, 1999). Because the chi-square test of model fit is highly sensitive to sample size - with the probability of rejecting a given model increasing as sample size increases - this fit statistic was not appropriate to use with my sample size of 500 (Bentler \& Bonnet, 1980; Bollen, 1989). After establishing adequate model fit, the case-level residuals for minimum standards were saved as an index of the attainability of people's standards for a spouse, where higher scores are indicative of less realistic spousal criteria. 
In the second step of the analysis, the residual-based index of unrealistic standards was used to predict participants' dating success (H1), relationship quality $(\mathrm{H} 2)$, expectations to marry (H3a), and psychological and behavioral investment in marrying (H4a). Specifically, these four hypotheses were tested by running a series of regression models in which each outcome was regressed on unrealistic standards while controlling for the aforementioned covariates. The potential moderating effects of age and relationship experience ${ }^{7}$ on the hypothesized associations between unrealistic standards and both expectations to marry (H3b) and investment in marrying (H4b) also were examined.

\footnotetext{
${ }^{7}$ Relationship experience was computed by multiplying the total number of committed relationships a participant had experienced by the reported average length of those relationships.
} 


\section{Chapter Three: Results}

\section{Calculating UnRealistic Standards}

Before testing the full structural model, confirmatory factor analysis was used to examine the adequacy of the latent constructs in the model. The indicators were forced to load only on their assigned factors and the two latent variables were allowed to correlate. Based on preliminary analyses which indicated that the error variances for global and relative mate value were positively and significantly related (likely due to measurement parallels), I also allowed the residuals of these two variables to correlate to account for relatedness not due to the factor of interest (e.g., Marsh \& Hau, 1996). Results of the CFA suggested that this base model was a close fit to the data: RMSEA $=.06(90 \% \mathrm{CI}$ : $.03-.08)$, CFI $=.99$, SRMR $=.03$. All items loaded significantly $(p<.001)$ on their intended latent variables, and, as expected, the mate value and mate availability constructs were positively and significantly correlated $(r=.37, p<.001)$.

The structural model illustrated in Figure 2 was tested in two steps. First, the main effects of mate value and mate availability on standards for a marriage partner were examined by simultaneously regressing mate standards (an observed variable) on both latent constructs. As hypothesized, there was a significant positive association between overall mate value and mate standards; the greater individuals' own desirability as a partner, the higher their reported criteria for a spouse $(\beta=.46, p<.001)$. Unexpectedly, no significant association was detected between the availability of desirable partners and the stringency of individuals' mate standards $(\beta=-.03, n s)$. Thus, although preliminary analyses revealed that mate availability was at least marginally associated with reported standards when considered independently $(\beta=.10, p=.06)$, this association disappeared entirely when mate value was included in the model. 


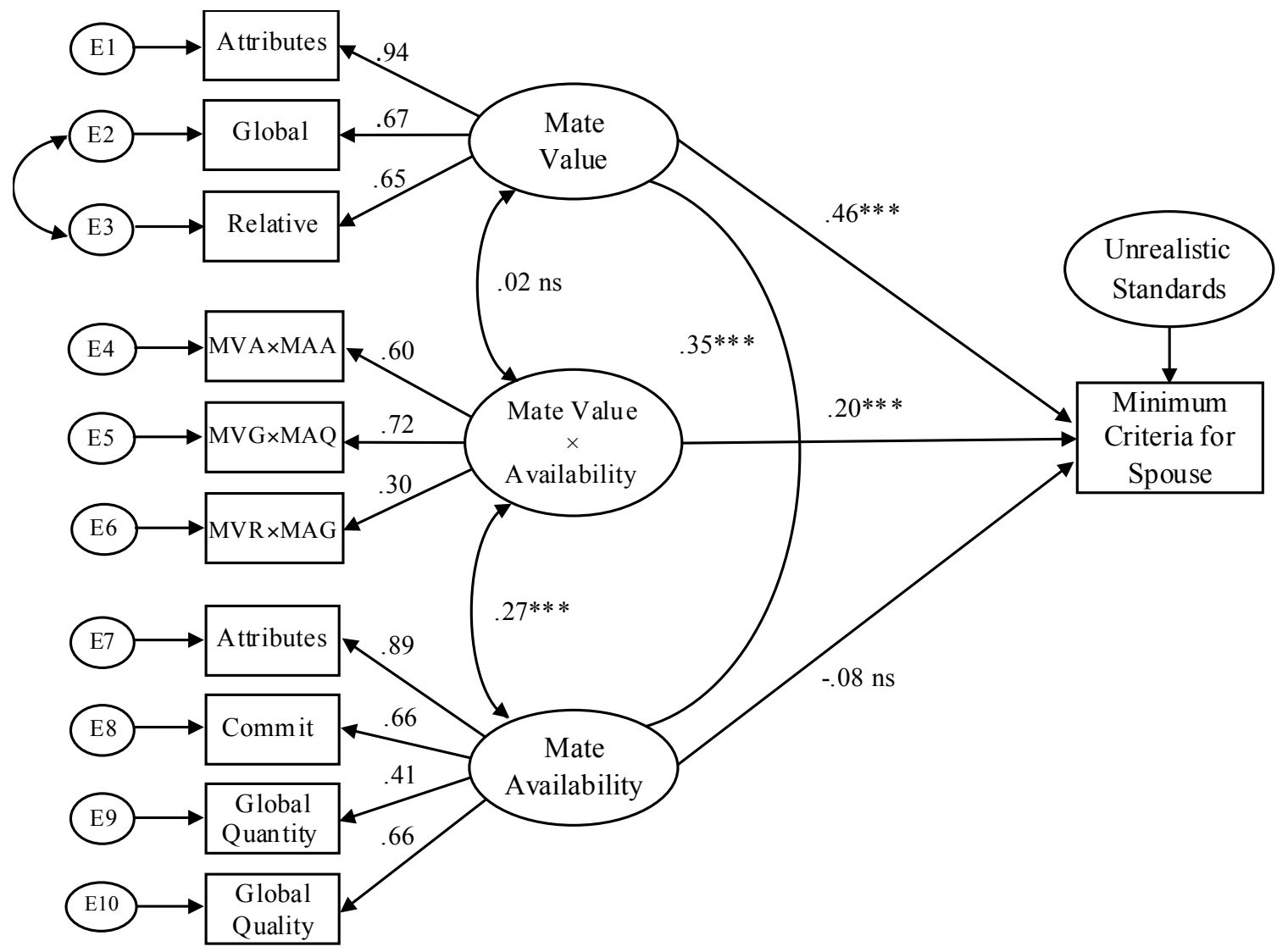

Figure 2. Latent interaction model quantifying unrealistic standards for a marriage partner. Path coefficients are standardized and all factor loadings are significant at the $p<.001$ level. $* * * p<.001$.

Next, to test for moderation between participants' mate value and their access to desirable partners, a latent interaction construct was added to the model (as described above) and mate standards was simultaneously regressed on all three latent variables. Results of the hypothesized latent interaction model are shown in Figure 2. Overall, the model exhibited a very good fit to the sample data (RMSEA $=.06$ [90\% CI: .04-.07], CFI $=.96, \mathrm{SRMR}=.05)$ and accounted for approximately $18 \%$ of the variance in individuals' reported standards for a marriage partner. As in Step 1, mate value - but not mate availability - predicted the stringency of people's mate standards $(\beta s=.46, p<.001$, and $-.08, p<.10$, respectively). Importantly, the mate value $\times$ mate availability interaction 
was significantly associated with minimum standards $(\beta=.20, p<.001)$. This interaction is depicted graphically in Figure 3.

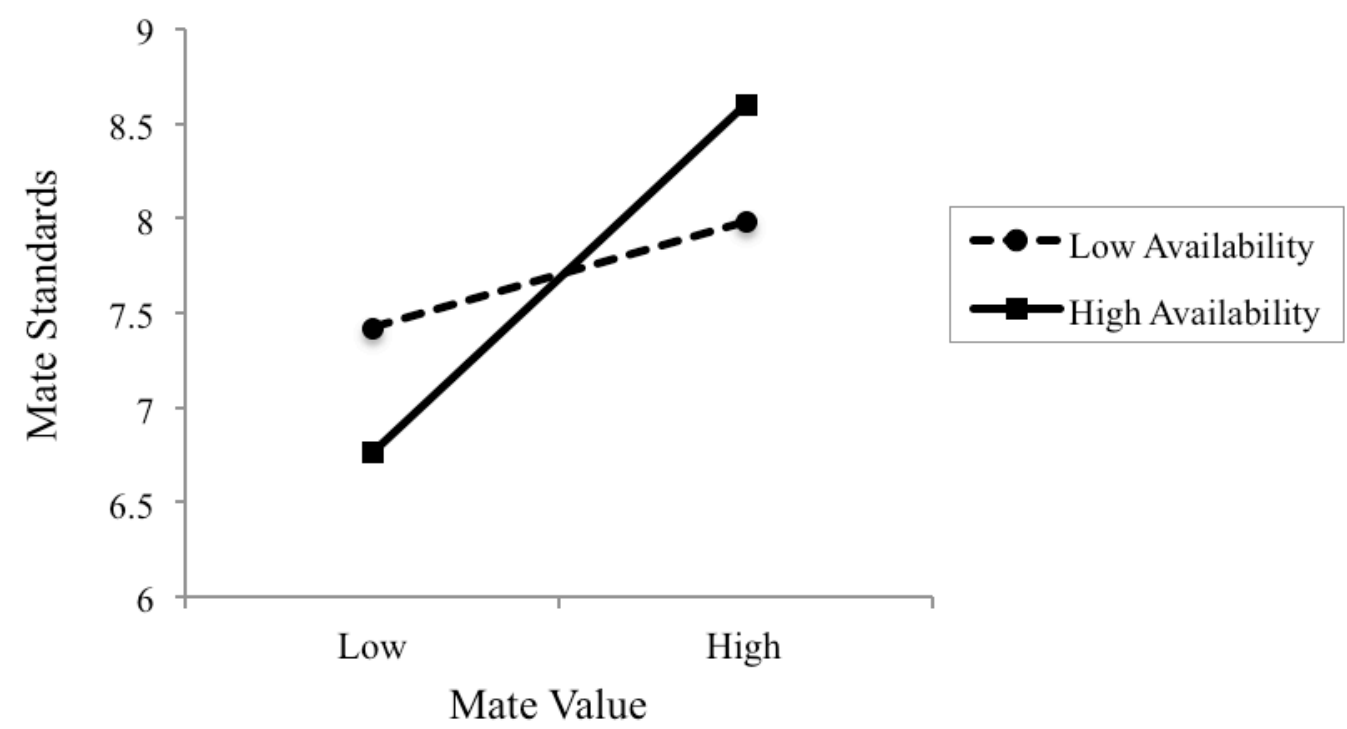

Figure 3. Graph of mate value $\times$ mate availability interaction predicting mate standards. High and low scores are 1.5 standard deviations above and below the mean, respectively.

Consistent with my predictions, the relationship between mate value and standards for a marriage partner was positive and significant at both high $(\mathrm{b}=.70, t=$ $9.65, p<.001)$ and low $(\mathrm{b}=.14, t=2.50, p<.05)$ levels of mate availability, but the association was stronger for people situated in more favorable mating markets. As mate availability decreased, so did people's propensity to hold standards that closely approximated their own desirability as a partner. However, the lines plotted in Figure 3 revealed an unanticipated finding: whereas the slopes of the regression lines followed the predicted pattern, the intercept of the line depicting the association between mate value and mate standards at low levels of mate availability was higher than expected. If people calibrate their standards to reflect the favorability of their actual partnering opportunities, we would expect individuals with low mate value and low mate availability to hold mate 
standards that are as low as - if not lower than - those who have low mate value and high mate availability. But this was not the case in my sample. Instead, singles with belowaverage mate value and low mate availability actually held higher standards than their low value-high availability counterparts. Thus, as the availability of desirable partners decreased, people with low mate value tended to calibrate their standards less accurately.

This systematic tendency for individuals with particularly poor opportunity structures to hold unwarrantedly high spousal standards has important implications for the present study. Specifically, because my measure of the attainability of people's standards is based on individual-level deviations from the sample norm, the index most likely underestimates unrealistic standards among individuals who fall in the lower quadrant on both mate value and mate availability (given their poor levels of calibration at the sample-level). Despite affecting only a subset of the sample, such underestimation may make it more difficult to detect significant associations between unrealistic standards and partnering outcomes. As a result, the following analyses should be viewed as providing conservative tests of the study's hypotheses.

\section{HyPOTHESIS TESTING}

Descriptive statistics. Correlations and descriptive statistics for all variables included in the regression analyses are presented in Table 2. Consistent with past work suggesting that women may hold less attainable standards for a marriage partner than their male counterparts (Bredow \& Huston, 2009), women's mate standards were significantly less realistic than those reported by men, $t(500)=-2.38, p<.05$. Three of the nine remaining control variables also were significantly associated with the attainability of individuals' mate standards. Specifically, people belonging to nonCaucasian ethnicities and those involved in romantic relationships reported less realistic 
standards than did Caucasians and individuals who were romantically uninvolved, $t(500)$ $=-2.52, p<.05$ and $t(500)=-2.24, p<.05$, respectively. The salience of people's standards for a marriage partner also was significantly correlated with unrealistic standards, such that people with more salient criteria tended to hold less realistic mate standards than individuals with less salient criteria $(r=.17, p<.001)$. Age, previous marital status, and dispositional variables such as global positivity or attachment anxiety were not significantly related to the attainability of people's mate standards.

Before testing my hypotheses, I performed independent samples $t$ tests to determine whether values on any of the outcome variables differed as a function of gender. Of the 13 analyses run, only one was statistically significant: women reported being involved in longer committed relationships over the course of their lives than did men, $t(461)=-2.72, p<.01$. Preliminary analyses also indicated that gender did not moderate any of the hypothesized associations between unrealistic standards and partnering outcomes; thus, all analyses were conducted with gender combined. In contrast, preliminary analyses exploring the influence of age on the questions of interest revealed a few odd associations between unrealistic standards and partnering outcomes among individuals at the very top of the age range (i.e., marginally significant curvilinear effects of age such that the hypothesized associations would disappear or reverse among people several $S D$ above the mean age). Because these age-related abnormalities suggest that partnering processes may operate differently among people who are far past the normative age for marrying, the following analyses excluded individuals who were more than $3 S D$ above the mean on age (i.e., age 63 and older; $\mathrm{n}=6$ ). 


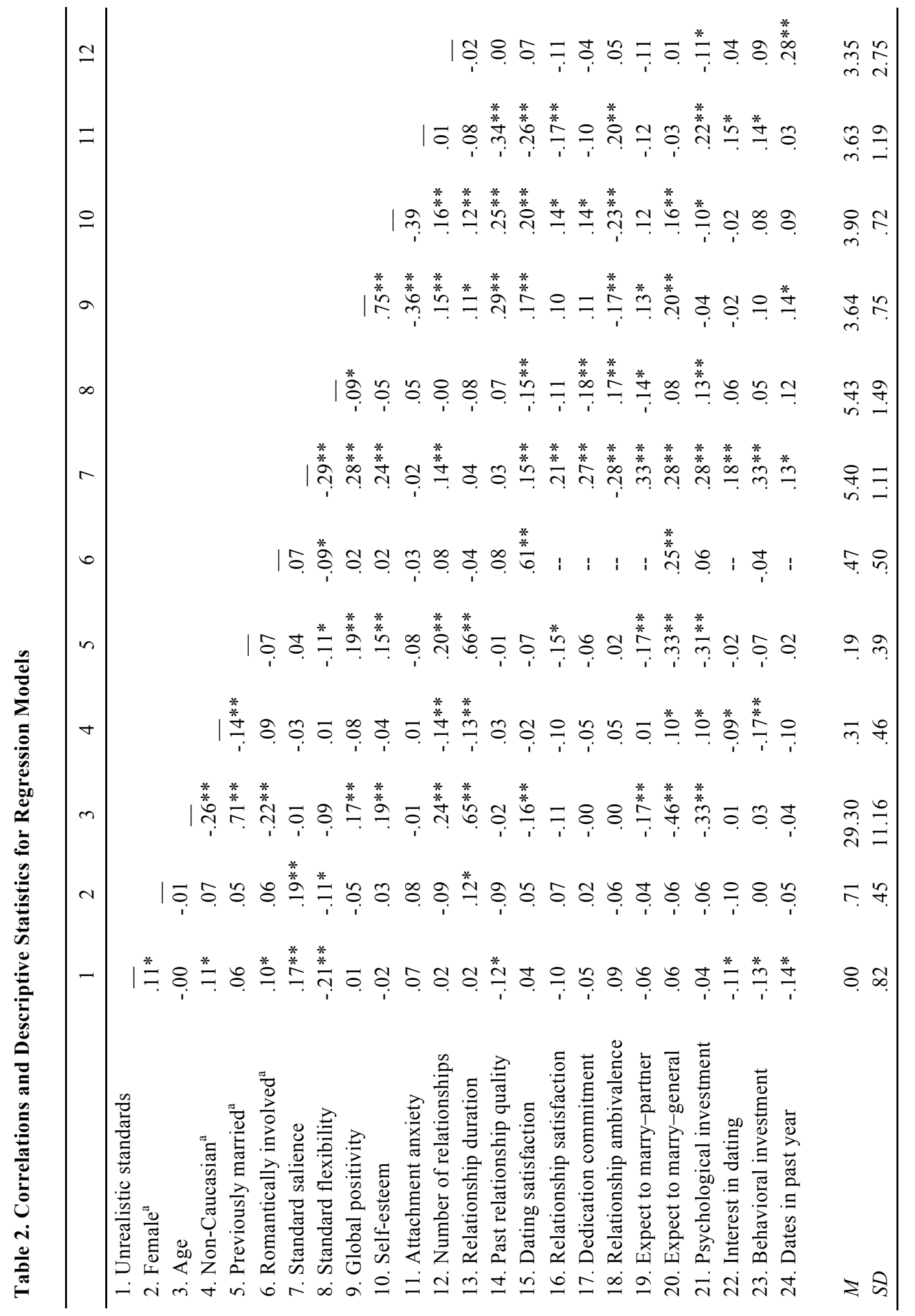




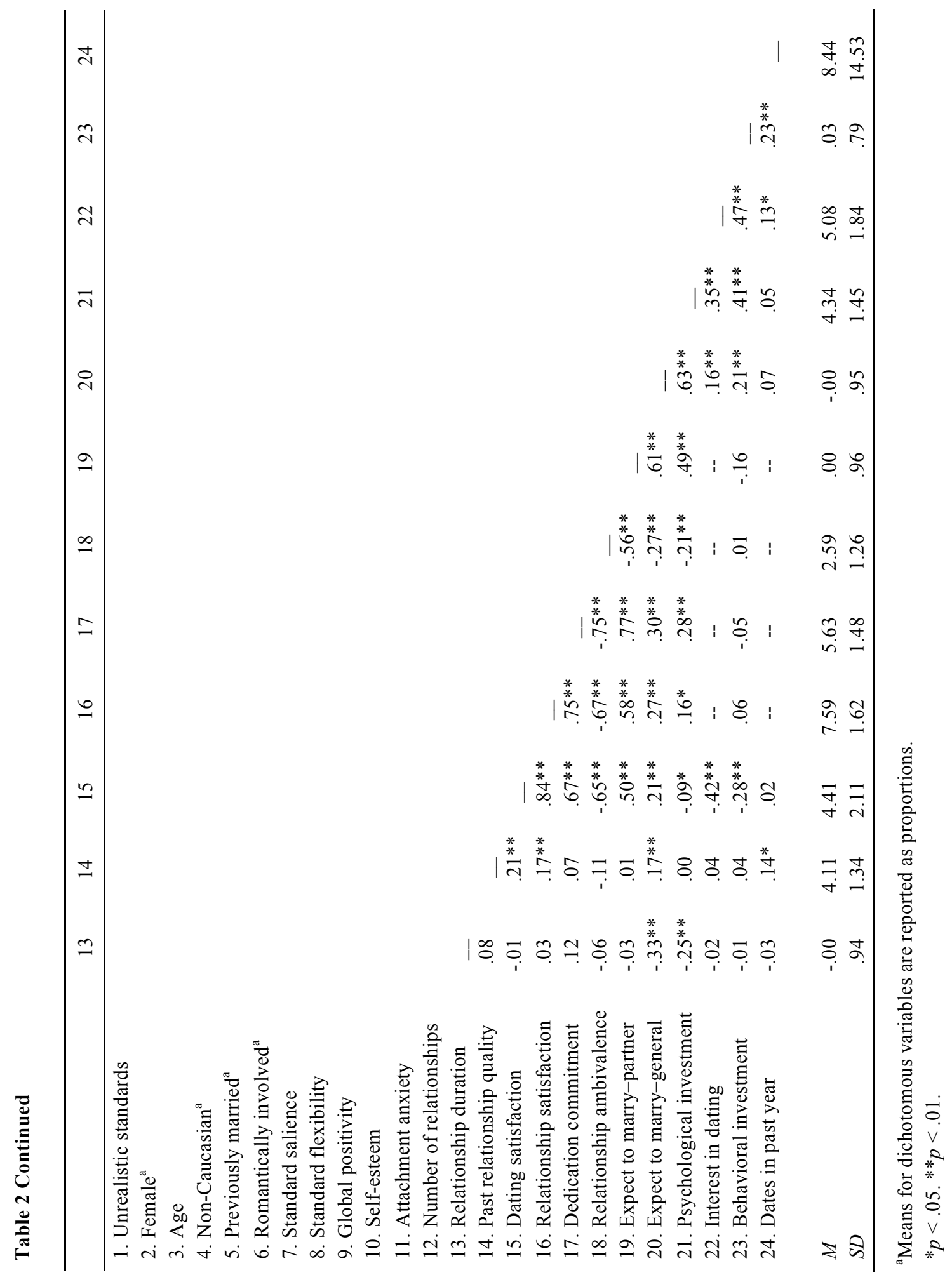


Unrealistic standards and dating success. Hypothesis 1 predicted that the less realistic people's standards for a marriage partner, the less successful they will be at dating, as evidenced by a lower ability to establish and maintain relationships, lower quality past relationships, and lower dating satisfaction. To examine this hypothesis, I estimated a series of regression models in which each potential outcome was regressed on unrealistic standards and the controls (i.e., gender, age, ethnicity, marital history, relationship status, standard salience and flexibility, global positivity, self-esteem, and attachment anxiety). Importantly, to avoid counting a voluntary lack of dating experience as a "lack of success," the dating success analyses excluded individuals who indicated they had never desired or pursued any exclusive/committed relationships. Results of these analyses are presented in Table 3 .

As the table reveals, only one of the four dating success outcomes was significantly associated with the attainability of people's spousal standards. Counter to my expectations, unrealistic standards did not predict the number of committed relationships people had been involved in over the course of their lives $(\beta=-.00, n s)$, the duration of these committed relationships $(\beta=-.01, n s),{ }^{8}$ or people's satisfaction with the current state of their love lives $(\beta=-.05, n s)$. However, the attainability of people's criteria was significantly associated with the quality of their past romantic relationships $(\beta=-.12, p<.05)$. As expected, individuals who held less realistic standards for a marriage partner reported lower quality past relationships than did those with more realistic criteria. Taken together, these findings provide mixed support for my hypothesis; whereas people with low versus high levels of unrealistic standards were

\footnotetext{
${ }^{8}$ To examine the possibility that the attainability of individuals' reported standards may be more closely linked to their recent relationship experiences than to their lifetime experiences, the analyses also were conducted using the number and duration of relationships individuals experienced in the past five years. The results from these analyses were substantively identical to those using people's lifelong relationship histories.
} 


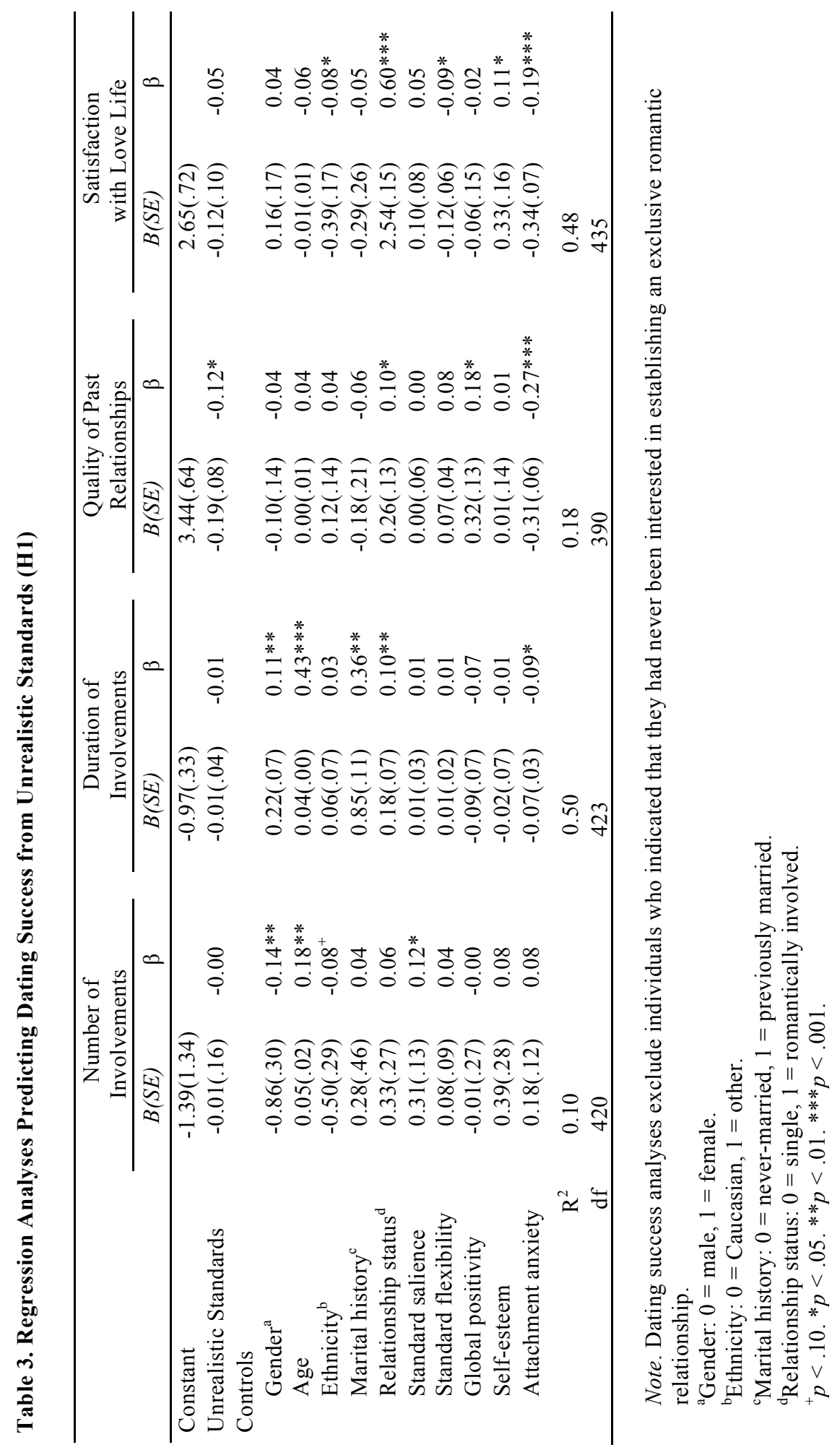


equally likely to establish and maintain romantic relationships - and reported being comparably happy with their present love lives - those with less realistic standards were more likely to report having a history of low quality romantic involvements.

Unrealistic standards and relationship quality. Based on the notion that people with less attainable criteria may have to settle for "subpar" partners in order to partner at all, my second hypothesis predicted that partnered individuals who hold less realistic mate standards will be involved in lower quality relationships than individuals with more realistic criteria. Following the procedure described above, I tested this prediction by regressing each outcome on unrealistic standards while controlling for the aforementioned covariates. Given that relational outcomes such as dedication or ambivalence may be confounded with the length of time couples have been together, relationship length also was included as a control. The results of these analyses are presented in Table 4. As expected, holding less realistic standards for a marriage partner was consistently and significantly linked to lower perceived relationship quality. Compared to those with more attainable criteria, individuals with less realistic standards reported being less satisfied with their romantic relationships $(\beta=-.15, p<.05)$, less dedicated to maintaining their relationships in the future $(\beta=-.13, p<.05)$, and more ambivalent about being involved with their current partners $(\beta=.20, p<.01)$.

Unrealistic standards and expectations to marry. Drawing on the idea that repeated partnering difficulties may lead people with less attainable criteria to view their marital prospects less favorably, Hypothesis 3a predicted that individuals who hold less realistic standards for a marriage partner will report lower expectations to marry than those with more realistic criteria. To test this idea, two separate regression analyses were conducted: one examining the influence of unrealistic standards on partnered individuals' expectations to marry their current partner and one examining the influence of unrealistic 


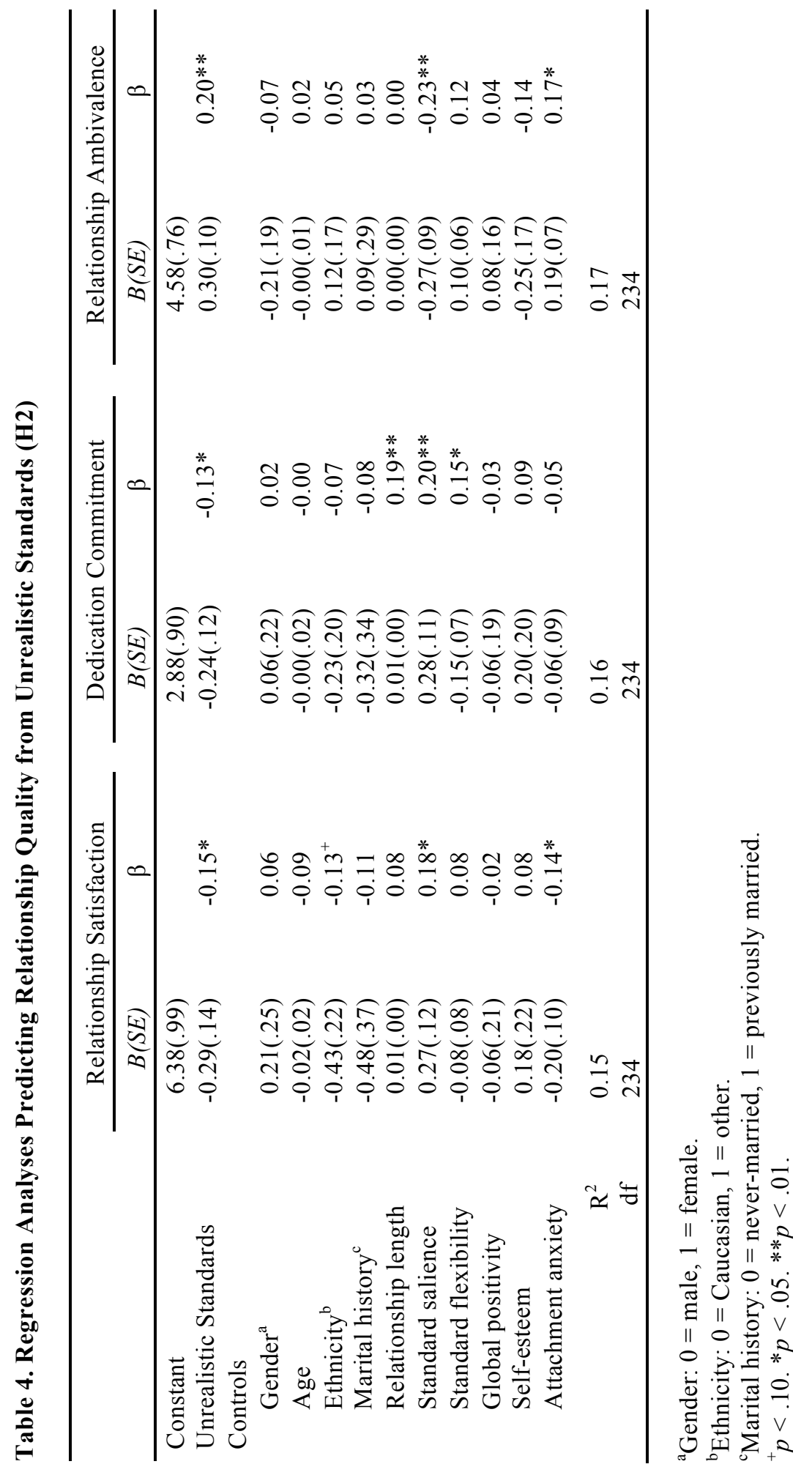


standards on all participants' general expectations to marry someday. The results presented in Table 5 provide partial support for my hypothesis. As expected, unrealistic standards negatively and significantly predicted individuals' expectations to marry their current partner; the less attainable people's spousal criteria, the lower their reported probability of eventually marrying their present partner $(\beta=-.13, p<.05)$. People's general expectations to marry, in contrast, were not significantly related to the attainability of their reported mate standards $(\beta=.03, n s)$. Individuals whose mate standards were less realistic given their own qualities and circumstances were just as likely to expect to get married someday as those with more realistic standards.

To test the possibility that the predicted negative effect of holding less realistic mate criteria on expectations to marry may be more pronounced among individuals who are older or who have more relationship experience (Hypothesis 3b), I then examined both age and relationship experience as potential moderators of the hypothesized association. Following the procedures outlined by Aiken and West (1991), two moderated regression analyses were run for each outcome variable - one testing the age $\times$ unrealistic standards interaction and one testing the relationship experience $\times$ unrealistic standards interaction. For each analysis, unrealistic standards, the moderator (i.e., age or relationship experience), and the control variables were entered initially, and the respective interaction term was entered in Step 2. Surprisingly, results from these analyses revealed that none of the four interaction terms were significant. Counter to my hypothesis, the associations between the attainability of people's mate standards and their expectations to marry (both with respect to their current partner and more generally) were no stronger for individuals who were older or who had accrued more relationship experience than for their younger, less experienced counterparts. 
Table 5. Regression Analyses Predicting Expectations to Marry from Unrealistic Standards (H3a)

\begin{tabular}{|c|c|c|c|c|}
\hline & \multicolumn{2}{|c|}{ Marry Partner } & \multicolumn{2}{|c|}{ Marry in General } \\
\hline & $B(S E)$ & $\beta$ & $B(S E)$ & $\beta$ \\
\hline Constant & $-1.30(.56)$ & & $-1.46(.32)$ & \\
\hline Unrealistic Standards & $-0.15(.08)$ & $-0.13 *$ & $0.03(.05)$ & 0.03 \\
\hline \multicolumn{5}{|l|}{ Controls } \\
\hline Gender $^{\mathrm{a}}$ & $-0.22(.14)$ & -0.10 & $-0.23(.08)$ & $-0.11 * *$ \\
\hline Age & $-0.02(.01)$ & $-0.17 *$ & $-0.04(.01)$ & $-0.42 * * *$ \\
\hline Ethnicity $^{\mathrm{b}}$ & $-0.07(.13)$ & -0.04 & $-0.03(.08)$ & -0.01 \\
\hline Marital history $^{\mathrm{c}}$ & $-0.24(.21)$ & -0.09 & $-0.17(.13)$ & -0.07 \\
\hline Relationship status & & & $0.25(.07)$ & $0.13 * *$ \\
\hline Relationship length & $0.01(.00)$ & $0.14^{*}$ & & \\
\hline Standard salience & $0.27(.07)$ & $0.29 * * *$ & $0.19(.04)$ & $0.22 * * *$ \\
\hline Standard flexibility & $-0.07(.05)$ & -0.11 & $-0.00(.03)$ & -0.00 \\
\hline Global positivity & $0.07(.12)$ & 0.05 & $0.19(.07)$ & $0.15 * *$ \\
\hline Self-esteem & $0.03(.12)$ & 0.02 & $0.17(.08)$ & $0.13 *$ \\
\hline Attachment anxiety & $-0.06(.05)$ & -0.07 & $0.07(.03)$ & $0.09 *$ \\
\hline $\mathrm{R}^{2}$ & 0.23 & & 0.36 & \\
\hline $\mathrm{df}$ & 234 & & 490 & \\
\hline
\end{tabular}

${ }^{\mathrm{a}}$ Gender: $0=$ male, $1=$ female. ${ }^{\mathrm{b}}$ Ethnicity: $0=$ Caucasian, $1=$ other.

${ }^{c}$ Marital history: $0=$ never-married, $1=$ previously married.

${ }^{\mathrm{d}}$ Relationship status: $0=$ single, $1=$ romantically involved.

${ }^{+} p<.10 .{ }^{*} p<.05 .{ }^{*} p<.01 .{ }^{* * *} p<.001$

To further explore the unexpected finding that neither age nor relationship experience moderated the association between unrealistic standards and people's expectations to marry, I conducted a set of additional analyses examining the possibility that age might influence the link between unrealistic standards and marital expectations in a nonlinear fashion. Rather than continuously increasing as individuals move from young adulthood to old age, the negative effect of holding less realistic spousal criteria on marital expectations might increase with age, but only up to a certain point. Consistent with this idea, the interaction between the quadratic of age (i.e., age $\times$ age) and unrealistic standards significantly predicted partnered individuals' expectations to marry their current partner $(\beta=.22, p<.05)$. This interaction effect is plotted in Figure 4 , which 
shows the association between the attainability of people's mate standards and their expectations to marry their current partners at age 18 (approximately $1 S D$ below the mean), age 29 (the sample mean), and age 40 (approximately $1 S D$ above the mean). Although unrealistic standards were significantly and negatively related to expectations to marry at age $29(\mathrm{~b}=-.31, t=-2.70, p<.01)$, the attainability of people's mate criteria was not related to marital expectations at age $18(\mathrm{~b}=-.00, t=-0.09, n s)$ or age $40(\mathrm{~b}=-$ $.15, t=-0.87, n s)$. Further probing the interaction using a quadratic modification of Preacher, Curran, and Bauer's (2006) approach to calculating regions of significance revealed that unrealistic standards were significantly associated with lower expectations to marry one's partner only between the ages of 20.10 and 34.28 . The age ${ }^{2} \times$ unrealistic standard interaction did not significantly predict people's general expectations to marry.

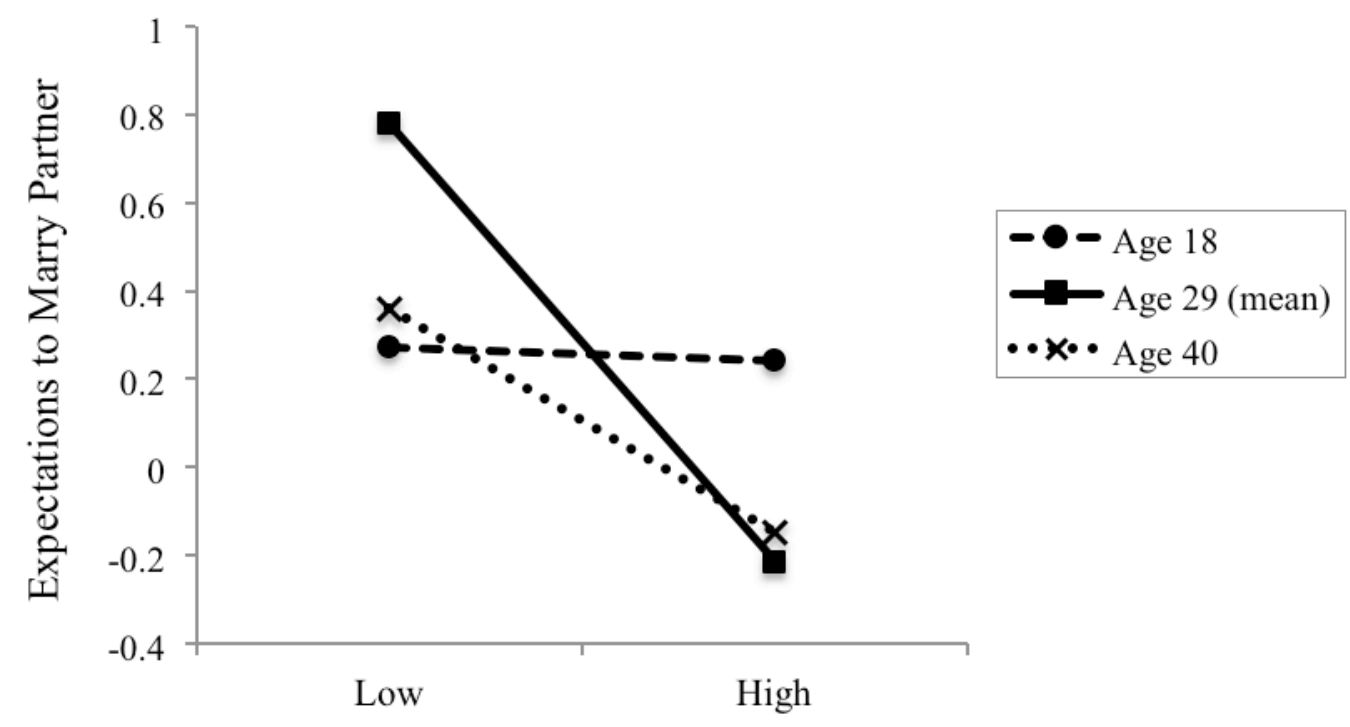

Unrealistic Standards

Figure 4. Graph of the age ${ }^{2} \times$ unrealistic standards interaction predicting people's expectations to marry their current partners (standardized). High and low scores on unrealistic standards are 1.5 standard deviations above and below the mean, respectively. The graphs reflect simple slopes when all controls are at zero (continuous predictors were centered prior to analysis). 
Unrealistic standards and investment in marrying. Lastly, I examined the prediction that people who report less realistic standards for a marriage partner will be less psychologically and behaviorally invested in marrying than those who report more realistic criteria (Hypothesis 4a). Following the same procedure described above, this hypothesis was tested using a series of regression analyses in which each of the four investment outcomes (psychological investment in marrying, interest in dating, behavioral investment in finding a partner, and dating behavior) were regressed on unrealistic standards and the control variables. For behavioral investment, the number of months out of the past year that participants had been single (i.e., not romantically involved) also was included as a control. The results of these analyses are presented in Table 6.

Providing consistent support for my hypothesis, unrealistic standards were significantly and negatively related to all four indicators of investment in marrying. As shown in the table, individuals who reported less realistic standards for a marriage partner reported being less psychologically invested in marrying than people with more attainable standards $(\beta=-.11, p<.01)$, and unpartnered individuals with less realistic criteria reported lower interest in dating than their more realistic counterparts $(\beta=-.13, p$ $<.05)$. A similar pattern was apparent in the behavioral indicators: single and casually dating individuals who held less attainable criteria for a spouse were less behaviorally invested in looking for a suitable partner $(\beta=-.17, p<.01)$ and reported going on fewer dates in the past year $(\beta=-.13, p<.01)$ than individuals with more attainable criteria.

As with expectations to marry, I also tested age and relationship experience as potential moderators of the link between unrealistic standards and individuals' investment in marrying (Hypothesis 4b). Again, two hierarchical regression models were run for each outcome, such that unrealistic standards, the moderator (i.e., age or relationship 


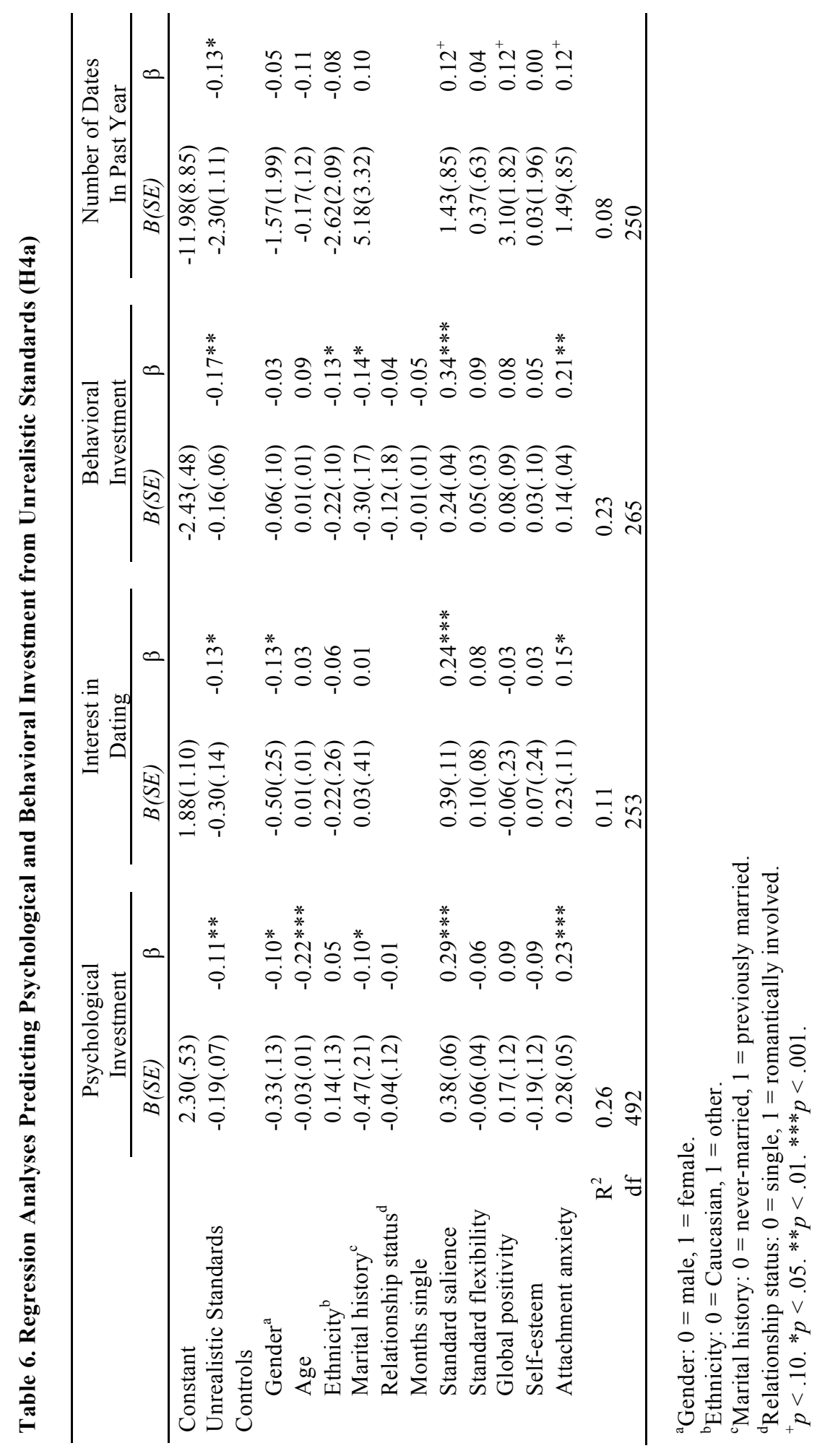


experience), and the controls were entered in Step 1, and the respective interaction term was entered in Step 2. Only two of the eight interaction models were significant. ${ }^{9}$ Whereas neither age nor relationship experience moderated the associations between unrealistic standards and people's psychological investment in marrying, interest in dating, or actual dating behavior, both the age $\times$ unrealistic standards interaction and relationship experience $\times$ unrealistic standards interaction significantly predicted individuals' behavioral investment in finding a marriageable partner $(\beta \mathrm{s}=-.17, p<.01$, and $-.14, p<.05$, respectively). These interactions are displayed graphically in Figure 5 .

Consistent with my hypothesis, the negative influence of possessing unrealistic standards on individuals' behavioral investment in finding a marriage partner was significantly stronger for individuals who were older and had more relationship experience than for their younger, less experienced counterparts. In fact, as Figure 5 illustrates, unrealistic standards were largely unrelated to behavioral investment among young adults $(\mathrm{b}=.03, t=0.34, n s$, at age 18) and individuals with low relationship experience ( $\mathrm{b}=-.06, t=-0.91, n s)$, but became increasingly tied to people's behavioral investment as age and relationship experience increased. Notably, both the age $\times$ unrealistic standards and relationship experience $\times$ unrealistic standards interactions remained significant even when the other moderator was controlled (e.g., age $\times$ unrealistic standards while controlling for relationship experience). This suggests that despite a fair amount of overlap between the two constructs $(r=.53, p<.001)$, the detected effect of relationship experience on the association between unrealistic standards and behavioral investment in finding a partner was not simply due its shared variance with age (or vice versa).

\footnotetext{
${ }^{9}$ As with expectations to marry, additional analyses were conducted to explore the potential quadratic influence of age on the link between unrealistic standards and investment in marrying, but no significant effects were found.
} 


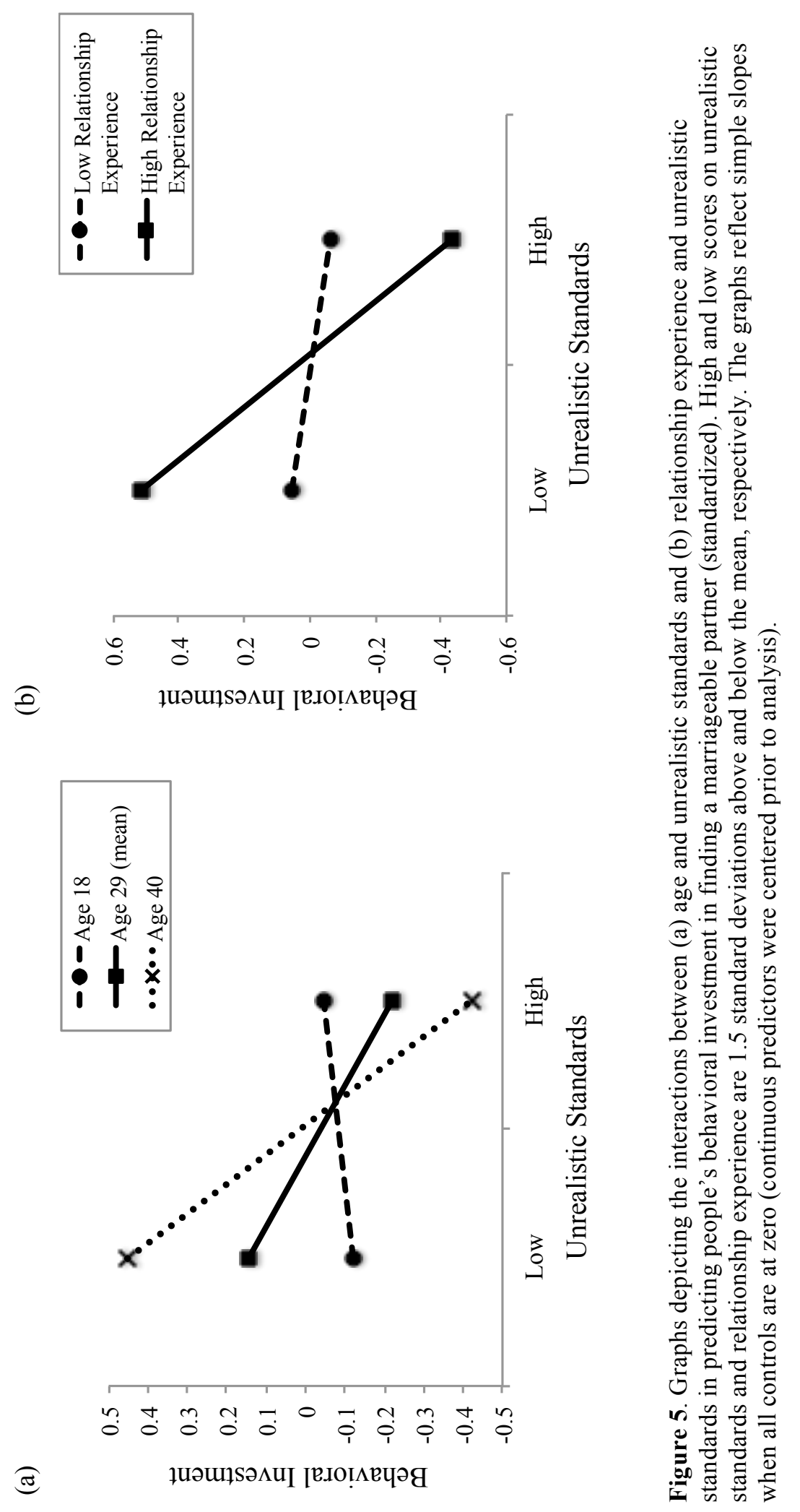




\section{Chapter Four: Discussion}

Although social scientists have frequently implicated unrealistically high mate standards as a barrier to marriage, this study is the first to attempt to actually quantify the attainability of people's spousal criteria and link unrealistic standards to partnering outcomes and behaviors. Specifically, my study breaks new ground by demonstrating not only that the attainability of people's standards for a marriage partner can be meaningfully quantified, but also that people with particularly unpromising circumstances (i.e., those with both low mate value and low mate availability) may systematically hold standards that are higher than is warranted. Moreover, in contrast to past studies which have generally uncovered null or even positive associations between high mate standards and partnering success (e.g., Bredow et al., 2011; Raley \& Bratter, 2004), my work shows that holding unrealistically high standards is linked to a number of outcomes indicative of partnering difficulties, including lower quality past and present romantic relationships, lower expectations to marry one's current partner, and lower investment in marrying. These contributions are discussed in turn below.

\section{Calculating UnRealistic Spousal Standards}

A central challenge in understanding the role of the attainability of people's standards in the partnering process is identifying an appropriate benchmark or baseline for what is "realistic." Past work has often treated high standards and unrealistic standards as largely interchangeable, assuming, for instance, that people who report more stringent standards for a mate will have greater difficulty securing a partner who meets their criteria. But this is not always the case. Indeed, theory suggests that - regardless of the absolute stringency of their criteria - people's standards should be more attainable the more closely they reflect their own social desirability as well as their access to desirable 
potential partners. Building on this theoretically grounded conceptualization of what makes people's standards more or less realistic, the residual approach used in the present study offers a new, demonstrably valuable, way of capturing the attainability of people's spousal criteria. Specifically, by operationalizing unrealistic standards as people's tendency to hold mate criteria that are higher than would be expected based on their mate value, the favorability of their marriage markets, and the interaction between the two, I was able to isolate the relative attainability of people's standards from the absolute stringency of their criteria and produce an index that predicted partnering outcomes in unique and meaningful ways. Indeed, when my regression analyses were run using absolute rather than unrealistic standards to predict people's partnering outcomes (analyses not shown here), the results were remarkably consistent with past work revealing null or sometimes positive associations between high mate standards and relationship and partnering success.

An additional unique strength of the measure of unrealistic standards used in this study is that it utilized both self- and peer-reported information to estimate participants' desirability as a spouse and marriage market conditions. Although aggregating individuals' self-ratings with those obtained from knowledgeable informants has become the gold standard for assessing attributes and behaviors in the personality literature (e.g., Connelly \& Ones, 2010; Vazire, 2010), this is the first study to use this approach to estimate people's mate value or the composition of their marriage markets. Given evidence that people overestimate the desirability of their attributes in some contexts (e.g., Taylor \& Brown, 1988), and underestimate their positive traits in others (e.g., Kirsner, Figuerdo, \& Jacobs, 2003), combining people's internal perceptions of their qualities with the external insights of their peers should yield a more accurate, wellrounded perspective of their "true" mate value than relying on self-reports alone (c.f. 
Hofstee, 1994; Hogan, 1998). Moreover, although little is known about the accuracy of self-ratings of external factors such as the availability of desirable partners, there is reason to believe that self-reported mate availability may also be tainted by various biases. For instance, to the extent that partnered individuals derogate their alternatives in order to maintain more positive impressions of their own partners (e.g., Buunk \& VanYperen, 1991; Van Lange \& Rusbult, 1995), people who are romantically involved may tend to assess their mating markets less favorably than is truly warranted. Thus, aggregating self- and peer-reports of people's market conditions should provide a more balanced perspective than relying solely on participants' own perceptions of the availability of desirable partners.

In support of the validity of this approach, my analyses revealed that, compared to alternative approaches (i.e., using self-reports alone, using peer-reports alone, or entering self-and peer-reports as separate indicators of each construct), averaging self- and peerreports on parallel measures to create indicators of mate value and mate availability (a) produced indicators with greater reliability, (b) accounted for greater variance in the corresponding latent factors, and (c) demonstrated a better fit to the data. Perhaps most importantly, when unrealistic standards were estimated using latent indicators that were constructed solely from self-reports, the detected associations between the attainability of people's mate standards and their partnering outcomes fell below significance for all but two of the variables (i.e., relationship ambivalence and past relationship quality). Taken together, these results highlight the value of adopting a multi-informant approach when assessing partnering constraints and suggest that the greater reliability and accuracy afforded by utilizing both self- and peer-reports may have been key to uncovering the present findings. 
Consistent with the substantial body of work suggesting that people's criteria for a long-term partner tend to reflect their own mate value (e.g., Kenrick et al., 1993; Sprecher \& Regan, 2002), the latent construct capturing participants' overall desirability as a marriage partner was strongly associated with people's reported spousal standards. Thus, in support of evolutionary and exchange accounts of mate selection, people's mate standards appear to be closely tied to their own value as a partner when even when a more "objective" measure of mate value is used (i.e., one that reflects more than just selfperceptions). Individuals' marriage market conditions, in contrast, did not predict their criteria for a marriage partner above and beyond considerations of their mate value. In fact, despite evidence suggesting that the availability of desirable partners influences people's views of their marital prospects (Bredow et al., 2011), as well as their actual likelihood of marrying (e.g., Lichter et al., 1992; Wood, 1995), the favorability of participants' marriage markets did not directly influence the stringency of their requirements for a spouse. Mate availability did, however, moderate how closely individuals calibrated their standards to reflect their mate value. Although having more to offer as a partner was associated with asking for more in a mate regardless of the composition of people's marriage markets, this association was considerably more pronounced for individuals who encountered ample desirable singles than for those who encountered fewer marriageable partners. Thus, as would be expected, high mate value individuals who had greater access to desirable potential partners tended to report higher standards for a marriage partner than comparably desirable individuals who were embedded in less favorable marriage markets.

Intriguingly, this pattern did not hold up for participants who were below average in mate value. Rather than holding spousal standards that were appreciably lower than those of their better situated counterparts, individuals who were low in both mate value 
and mate availability held somewhat higher criteria for a partner than people who had low mate value but better mating markets. This finding is directly counter to theory suggesting that a combination of lower social desirability and lower availability of desirable partners should - on average - lead people to adopt lower standards in order to optimize their chances of partnering. Given evidence that low mate availability is, indeed, more likely to hinder people's entry into marriage when mate value is also low (e.g., McLaughlin \& Lichter, 1997), these results suggest that participants with low mate value and low access to desirable partners held standards that were systematically higher than would be expected based on their circumstances. Indeed, for these individuals, holding unattainably high standards for a marriage partner appeared to be a matter of practice, rather than a deviation.

Although unexpected, the discovery that individuals who are low in both mate value and mate availability may routinely undercalibrate their standards for a marriage partner is consistent with past work suggesting that, in certain situations, holding unrealistically high standards for a partner may serve a self-protective function. For instance, Edin and colleagues $(2000,2005)$ have suggested that low-income women may commonly hold mate criteria that are unrealistic given their own mate value and the type of men available to them - and that they likely exercise considerable wisdom in doing so. Whereas the risk of holding low standards may be relatively low for undesirable individuals who are embedded within high quality mating markets (i.e., even the worst partners are only so bad), the consequences of holding low mate standards when one is surrounded by low-quality, generally "unmarriageable" partners is much higher. Thus, to avoid marrying people who are - objectively speaking - not marriage material, such individuals may routinely adopt standards that are higher than is warranted (and higher than they are likely to be able to get). 
Unfortunately, because the present study assessed the attainability of people's standards for a marriage partner using deviations from the norm, the systematic tendency for individuals with low mate value and low mate availability to adopt unrealistically high standards likely led me to overestimate the actual attainability of these individuals' criteria. In other words, to the extent that the regression line depicting the mate standards of individuals with low mate value and low mate availability was higher than it would have been had their criteria been calibrated more accurately, estimates of unrealistic standards for these people will be artificially low. It is important to note, however, that although this reduced precision in estimating unrealistic standards is clearly not ideal, it should not be interpreted as undermining the study's findings. If anything, this limitation actually accentuates the significance of the detected effects because underestimating unrealistic mate standards among those most likely to score high on such a measure should make it more rather than less difficult to link the attainability of people's criteria to their partnering outcomes.

\section{UNREALISTIC STANDARDS AND DATING/RELATIONSHIP SUCCESS}

The second major goal of my study was to examine whether holding less realistic spousal standards - as measured using the approach described above - is associated with attitudes and behaviors that are indicative of partnering difficulties and, ultimately, with a reduced likelihood of marrying. Considered in tandem, the results from my analyses linking unrealistic mate criteria to indicators of individuals' dating success and current relationship quality paint an interesting picture of the pathways through which the attainability of people's standards might affect the partnering process. Specifically, although people who reported less realistic mate standards established as many committed relationships - and maintained them for about as long - as their more 
"pragmatic" counterparts, they appeared to do so at the cost of quality. In addition to reporting a history of less satisfying, lower quality romantic relationships, individuals with less attainable mate standards tended to evaluate their current relationships less positively than people with more attainable criteria; indeed, partnered individuals who held less realistic standards for a marriage partner were less satisfied with their relationships, less dedicated to continuing their relationships in the future, and more ambivalent about being involved with their partners. Thus, despite being involved in their fair share of relationships over their lifetimes, people with less realistic standards appear to have greater difficulty establishing high-quality relationships, which reduces, in turn, the probability that their relationships will lead to marriage (e.g., Brown, 2000).

Given that individuals with less realistic standards tended be more dissatisfied with their past and present dating relationships than those who held more attainable criteria, it is somewhat surprising that the attainability of people's standards for a spouse was not associated with how satisfied they were with their current love lives. One possible explanation for this unexpected null result is that the nature of the link between unrealistic standards and satisfaction with one's love life may actually differ based on whether or not people are currently involved in a romantic relationship. For instance, although we would expect partnered individuals to base their current dating satisfaction largely on evaluations of their present romances (such that people who are less happy with their relationships will also be less happy with their love lives), unpartnered individuals' dating satisfaction may primarily reflect how content they are with their current singlehood. The more content or resolved a person is about being relationally single, the more satisfied he or she is likely to be. Interestingly, this suggests that to the extent that people with less realistic standards tend to cope with their circumstances by placing less importance on marriage and partnering (as discussed further in the next 
section), unpartnered individuals with less realistic standards might actually report being more satisfied with their current love life (i.e., their current singlehood) than those with more attainable criteria.

Providing tentative support for this idea, exploratory analyses examining the moderating role of relationship status revealed a marginally significant interaction between unrealistic mate standards and relationship status in predicting people's satisfaction with their current love lives. Specifically, whereas holding less realistic mate standards was associated with lower dating satisfaction among individuals who were currently involved in a romantic relationship $(\mathrm{b}=-.21, t=-1.67, p<.10)$, maintaining less realistic criteria was actually linked to somewhat higher dating satisfaction among unpartnered individuals, although not significantly so $(\mathrm{b}=.11, t=0.81, n s)$. Although these marginal findings await replication, the detected pattern is consistent with the idea that disengaging from unattainable goals promotes greater subjective well-being (i.e., greater dating satisfaction; Carver \& Scheier, 1998; Wrosch et al., 2003) and provides at least suggestive evidence that the expected effect of unrealistic standards on dating satisfaction may be masked by the presence of singles who have already disengaged from the pursuit of a spouse. Ultimately, untangling these processes will require longitudinal analyses that can examine the interplay among the attainability of people's standards, their dating satisfaction, and their level of engagement in the partnering process over time.

\section{UNREALISTIC STANDARDS AND EXPECTATIONS TO MARRY/INVESTMENT IN MARRYING}

Given that an accumulation of negative partnering experiences should generally lead people to view their marital prospects less favorably (e.g., Bredow et al., 2011; Waller \& McLanahan, 2005), my study also examined the prediction that the attainability 
of people's spousal criteria would be associated with their expectations to marry as well as their level of investment in marrying. Consistent with my earlier results linking less realistic mate standards to involvement in poorer quality relationships, individuals who reported less attainable criteria for a marriage partner were significantly less likely to believe they would marry their current dating partner than those who held more attainable standards; interestingly, though, this link was significant only for individuals between the ages of 20 and about 34. Although unhypothesized, this quadratic interaction is notable because it suggests that, rather than becoming progressively more prominent as people age, the effect of less realistic standards on expectations to marry one's partner is only apparent at ages when people are most normatively considering marriage.

Curiously, despite evidence that the attainability of dating individuals' spousal standards was linked to their estimated likelihood of marrying their current partner, holding less realistic standards for a marriage partner did not appear to dampen people's more general expectations about whether they would marry someday. Indeed, even when searching for potential moderators or suppressors of this expected relation (e.g., age, relational experience, relationship status, desire to marry), the association between the attainability of people's mate standards and their general beliefs about their likelihood of marrying hovered consistently around zero. Although further research is needed to examine whether this unexpected finding would be replicated in another sample, the present results suggest that there may be some level of disconnect between people's specific experiences and relational expectations and their more global judgments of their marital prospects. That is, similar to the way people compartmentalize their relationship judgments (e.g., Neff \& Karney, 2002, 2005), individuals may tend to maintain global beliefs about their chances of marrying that are distinct from (and perhaps less based in reality than) their more specific partnering evaluations. Further exploring this potential 
cognitive disconnect - as well as its possible implications for people's partnering behaviors - is an important direction for future research.

In light of the unanticipated finding that the attainability of people's standards for a marriage partner had little influence on their reported expectations to eventually marry, it is notable that unrealistic standards nevertheless predicted all four indicators of people's investment in marrying. Consistent with past work suggesting that it is both common and psychologically adaptive for individuals to disengage from pursuing goals that they consistently fail to meet (e.g., Wrosch et al., 2003), individuals who held less realistic spousal standards placed less value on the importance of getting married, were less likely to be actively engaged in looking for a marriage partner, were less interested in dating, and participated in less actual dating behavior than those with more realistic standards. Interestingly, of these four associations, only the link between unrealistic standards and people's behavioral investment in finding a partner was significantly moderated by age and relationship experience. Although people with less realistic standards held less positive attitudes about marriage and dating than their more realistic counterparts, these negative attitudes did not tend to become more pronounced with age or accumulated relationship experience. This was not the case for people's behaviors. Indeed, the older individuals were and the more relationship experience they had accrued, the more they tended to behaviorally disengage from partnering in response to holding less attainable standards. ${ }^{10}$ Although not a substitute for analyses examining intraindividual change over time, these results provide suggestive evidence that the bleak

\footnotetext{
${ }^{10}$ Given its conceptual overlap with people's behavioral investment in seeking out a suitable partner, it is interesting that people's actual dating behavior was not moderated by age or relationship experience. Although this discrepancy might suggest that age and relationship experience affect the links between unrealistic standards and these outcome variables differently, is equally likely that my inability to detect a significant interaction effect reflects the less reliable measurement of the dating behavior variable (e.g., use of a single-item indicator). Future research using a more multidimensional index of dating behavior is needed to distinguish between these two possible explanations.
} 
realities of holding unattainable spousal standards may become more apparent to people as they age - and that they are reflected in people's behavior accordingly.

Taken together, the detected associations between unrealistic spousal standards and people's marital expectations and investment in marrying generally support my prediction that holding less attainable criteria would be related to important precursors of people's future marital behavior. Indeed, despite the surprising finding that holding less realistic standards did not predict individuals' general expectations to marry, both people's partner-specific marital expectations and their psychological and behavioral investment in marrying were linked to the attainability of their criteria for a partner. Given the established connections between these variables and people's demonstrated likelihood of marrying (e.g., Sassler \& Schoen, 1999; Waller \& McLanahan, 2005), the present findings provide compelling support for the argument that the attainability of people's standards matters for their marital behavior.

\section{LiMitATIONS AND FUTURE Directions}

Despite the many strengths of this study - including its innovative design, its use of a large, reasonably diverse sample of unmarried individuals and informants, and the numerous contributions noted in the preceding paragraphs - this work is not without its limitations. First, although my assessment of the attainability of people's mate standards is the first of its kind and represents a substantial improvement over past work in this area, my index of unrealistic standards was not able to capture the construct perfectly. A key limitation of using a deviation-based approach to assess unrealistic standards is that the resulting measure is, by definition, sample-dependent. Although using a large sample of singles drawn from a range of backgrounds reduced the risk that unrealistic standards were calculated from a highly idiosyncratic "norm," my estimates were still dependent on 
the extent to which people - at a sample level - calibrated their standards in a theoretically consistent manner. As a result, the tendency for individuals with both low mate value and low mate availability to hold unwarrantedly high mate standards likely resulted in underestimating unrealistic standards for these individuals, thus reducing the reliability of my measure. Given this limitation and the novel nature of my study, additional research is clearly needed to establish the validity of my measurement approach as well as to explore alternative methodologies that may provide better estimates of unrealistic standards for people with particularly poor partnering circumstances.

An additional, closely related limitation of the present study is that the effect sizes for my analyses linking unrealistic standards to partnering outcomes tended to be small by conventional standards (e.g., Cohen, 1988). These small effects are not surprising and are actually quite notable - given the tendency of my attainability index to underestimate unrealistic standards for certain subgroups. As noted earlier, the results reported in this study likely reflect a conservative estimate of the associations between the attainability of people's standards and their partnering outcomes and behaviors; had I been able to capture unrealistic standards more precisely among individuals in the lower quadrant on mate value and mate availability, the detected links likely would have been stronger. Nevertheless, one should be mindful of these effect sizes when interpreting the results. Indeed, given the difficulty of detecting moderators for associations that are small in magnitude (McClelland \& Judd, 1993), the present study's failure to detect moderating effects of age and/or relationship experience on the links between unrealistic criteria and several of the investment variables should be interpreted with caution.

Finally, it is important to note that, because the data examined in my study are correlational in nature, they cannot directly test the causal assumptions underlying my 
models. For instance, although I have characterized unrealistic standards as leading to diminished behavioral investment in marrying, it is possible that this relation is actually bidirectional, such that people who are less invested in presently seeking out a partner also are less concerned about calibrating their standards realistically. Although it is noteworthy that my chosen interpretation of the data is consistent with a substantial body of theory and qualitative work, disentangling the "true" causal models underlying the associations between unrealistic standards and partnering outcomes ultimately will require longitudinal research. Despite being grossly underutilized in the study of mate selection, longitudinal studies provide a powerful forum for understanding the pathways through which individuals' mate standards influence partnering processes and for examining interesting questions regarding the long-term consequences of maintaining unrealistic standards. Accordingly, I will be following a subset of the present sample over the next two to three years in order to more closely explore the causal relations among the attainability of people's reported mate standards and their partnering behaviors.

In addition to the future directions noted above, the current study raises a number of questions about the role of mate standards in partnering that would provide exciting avenues for future research. One important area that has received surprisingly little attention in the discourse on mate selection pertains to the stability of people's mate criteria over time. With the exception of a handful of studies providing mixed evidence for the short-term stability of mate standards in partnered individuals (e.g., Fletcher, Simpson, \& Thomas, 2000; Zenter, 2005), almost nothing is known about the extent to which unmarried people change their criteria for a partner as they age, as their partnering constraints change, or as they enter or exit relationships. Future research would also benefit from exploring potential moderators of these associations to discover whether 
certain people may be more likely to adjust or relax their criteria than others. Finally, given the increasing popularity of Internet dating services and other virtual methods of locating potential partners (e.g., Facebook), people's access to desirable potential mates may depend, in part, on their use of the Internet to search for a spouse. Although several of the items used to assess global mate availability in the present study were general enough to accommodate participants' (and informants') perceptions of their access to potential partners via the Internet, future investigations should more directly examine the role that Internet dating may play in affecting the calibration of individuals' mate standards.

\section{Conclusions}

So what are the consequences of chasing Prince (or Princess) Charming for individuals' partnering behavior? Does holding less attainable mate standards hinder people's ability to form relationships that eventually lead to marriage? Although definitive answers to these questions await future longitudinal work, the present study provides compelling evidence that the answer to the latter is "yes." Indeed, rather than indicating a fundamental disconnect between people's reported mate standards and their behavior - as social scientists have sometimes proposed - my work suggests that the pathways from mate standards to partnering behaviors and outcomes are simply more complicated than previous studies have typically accounted for (and require the use of more sophisticated measurement techniques than have generally been used). Regardless of the absolute stringency of the criteria they hold, individuals who maintain spousal standards that are less likely to be attainable given their qualities and circumstances tend to experience greater difficulty establishing satisfying romantic relationships, to report lower expectations to marry their current partners, and to be less psychologically and 
behaviorally invested in finding a suitable partner and marrying. These experiences, attitudes, and behaviors, in turn, may likely deter people's future entry into marriage. 


\section{Appendices}

\section{Appendix A: Standards for a Marriage Partner}

Many people have an idea of the kind of marriage partner they want. For each of the attributes listed below, please use a scale from 0-10 to indicate the minimum level of the characteristic a person would need to have for you to consider him/her an acceptable marriage partner.

For example, if the characteristic is "good-looking and sexy," a "0" indicates that a person would not need to be at all good-looking and sexy, a " 5 " indicates that a person would need to be somewhat good-looking and sexy, and a "10" indicates that a person would need to be extremely good-looking and sexy.

$\begin{array}{ccccccccccc}0 & 1 & 2 & 3 & 4 & 5 & 6 & 7 & 8 & 9 & 10 \\ \text { Not at all } & & & & & \text { Somewhat } & & & & & \text { Extremely }\end{array}$

1. Emotionally stable (e.g., able to control anger, not overly moody)

2. Kind and understanding

3. Well-educated

4. Has healthy and fit body

5. Sexually faithful

6. Has well-paying job/good career prospects

7. Good sense of humor

8. Intelligent

9. Adventurous and fun personality

10. Ambitious and hard-working

11. Good-looking and sexy

12. Dependable (e.g., follows through on commitments, handles money responsibly)

13. Sober and drug-free

14. Warm and emotionally expressive

15. Unselfish

16. Outgoing and sociable

17. Honest and trustworthy

18. Financially stable/good financial prospects 


\section{ApPendix B: Mate VAlue}

\section{Section A: Attribute-Based Measure}

\section{Self-Report Instructions}

For each of the following characteristics, please indicate on a scale from 0-10 how much you possess the attribute. For example, if the characteristic was "intelligent," choosing $\underline{\mathbf{0}}$ would indicate that you are not at all intelligent, choosing $\mathbf{5}$ would indicate that you are somewhat intelligent (average), and choosing $\mathbf{1 0}$ would indicate that you are extremely intelligent (much more intelligent than most people).

\section{Peer-Report Instructions}

For each of the following characteristics, please indicate on a scale from 0-10 how much [participant name] possesses the attribute. For example, if the characteristic was "intelligent," choosing $\underline{\mathbf{0}}$ would indicate that he/she is not at all intelligent, choosing $\underline{\mathbf{5}}$ would indicate that he/she is somewhat intelligent (average), and choosing $\underline{\mathbf{1 0}}$ would indicate that he/she is extremely intelligent (much more intelligent than most people).

$\begin{array}{ccccccccccc}0 & 1 & 2 & 3 & 4 & 5 & 6 & 7 & 8 & 9 & 10 \\ \text { Not at all } & & & & & \begin{array}{c}\text { Somewhat } \\ \text { Extremely }\end{array}\end{array}$

1. Emotionally stable (e.g., able to control anger, not overly moody)

2. Kind and understanding

3. Well-educated

4. Have healthy and fit body

5. Sexually faithful

6. Have well-paying job/good career prospects

7. Good sense of humor

8. Intelligent

9. Adventurous and fun personality

10. Ambitious and hard-working

11. Good-looking and sexy

12. Dependable (e.g., follow through on commitments, handle money responsibly)

13. Sober and drug-free

14. Warm and emotionally expressive

15. Unselfish

16. Outgoing and sociable

17. Honest and trustworthy

18. Financially stable/good financial prospects 


\section{Section B: Global Mate Value}

\section{Self-reported}

1. Thinking of the qualities that people consider necessary or desirable in a spouse, how would you rate yourself as a marriage partner at this point in time?

$\begin{array}{lllllllllll}0 & 1 & 2 & 3 & 4 & 5 & 6 & 7 & 8 & 9 & 10\end{array}$

I'd make a

terrible partner

I'd be a great catch

2. Once they got to know me, most men/women would consider me to be a desirable partner in a long-term relationship.

$\begin{array}{lllllll}1 & 2 & 3 & 4 & 5 & 6 & 7\end{array}$

Strongly

Disagree

Strongly

Agree

\section{$\underline{\text { Peer-reported }}$}

1. Thinking of the qualities that people consider necessary or desirable in a spouse, how would you rate [participant name] as a marriage partner at this point in time?

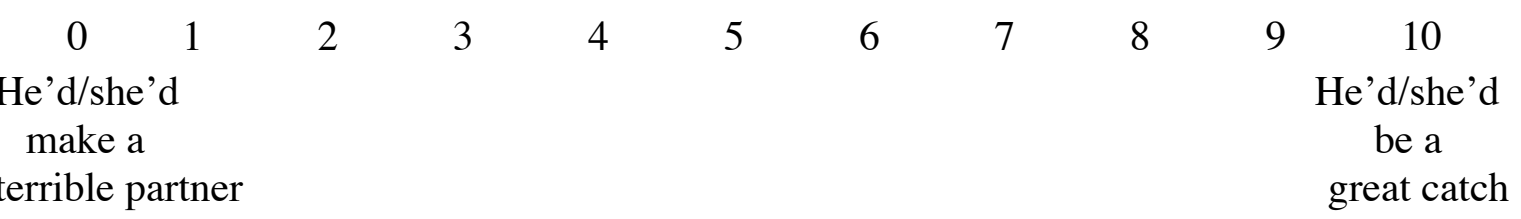

2. Once they got to know him/her, most men/women would consider [participant name] to be a desirable partner in a long-term relationship.

1

2

3

4

5

6

7

Strongly

Disagree

Strongly

Agree 


\section{Section C: Relative Mate Value}

\section{Self-reported}

1. I have more to offer as a romantic partner than most men/women my age.

1

$$
2
$$

3

4

5

6

7

Strongly

Disagree

Strongly

Agree

2. Thinking about the qualities that most people want or require in a spouse, how desirable would you be as a marriage partner compared to most of the unmarried men/women you know?

$\begin{array}{lllllll}1 & 2 & 3 & 4 & 5 & 6 & 7\end{array}$

Much less

desirable

Much more

desirable

\section{$\underline{\text { Peer-reported }}$}

1. [Participant name] has more to offer as a romantic partner than most men/women his/her age.
12
3
4
5
6
7
Strongly
Disagree
Agree

Strongly

2. Thinking about the qualities that most people want or require in a spouse, how desirable would [participant name] be as a marriage partner compared to most of the unmarried men/women you know?

$\begin{array}{ccccccc}1 & 2 & 3 & 4 & 5 & 6 & 7 \\ \text { Much less } & & & & & \text { Much more }\end{array}$

desirable

desirable 


\section{Appendix C: Mate Availability}

\section{Section A: Attribute-Based Measure}

\section{Self-report Instructions}

For the following set of questions, think about the men/women you encounter or interact with on a day-to-day basis who you could at least potentially begin a long-term romantic relationship with (e.g., those who are presumably single, of an appropriate age, etc.). This includes people who you encounter at work, at school, at the grocery store, at the gym, at a party or bar, or any number of other places where you spend your time. Using the scale below, please indicate how much you agree or disagree that most of the singles you meet possess each quality.

\section{Peer-report Instructions}

For the following set of questions, think about the men/women [participant name] encounters or interacts with on a day-to-day basis who he/she could at least potentially begin a long-term romantic relationship with (e.g., those who are presumably single, of an appropriate age, etc.). This includes people he/she may encounter at work, at school, at the grocery store, at the gym, at a party or bar, or any other places where he/she spends his/her time. Using the scale below, please indicate how much you agree or disagree that the single men/women [participant name] encounters tend to possess each quality.
1
2
3
4
5
6
7

Strongly

Disagree

Most of the eligible men/women I encounter/[participant name] encounters ...

1. are emotionally stable (e.g., able to control their anger, not overly moody).

2 . are kind and understanding.

3. are well-educated.

4. have healthy and fit bodies.

5. can be trusted to be sexually faithful.

6. have a good sense of humor.

7. are intelligent.

8. have adventurous and fun personalities.

9. are ambitious and hard-working.

10. are good-looking and sexy. 
11. are dependable (e.g., follow through on commitments, handle money responsibly).

12. are sober and drug-free.

13. are warm and emotionally expressive.

14. are unselfish.

15. have well-paying jobs/good career prospects.

16. are outgoing and sociable.

17. are honest and trustworthy.

18. are financially stable/have good financial prospects.

Single-item assessing potential partners' interest in marriage:

19. are interested in making a commitment and getting married.

\section{Section B: Global Mate Availability}

\section{Self-reported}

1. In general, how available are single men/women who would make good marriage partners?

12

23

34

5

6

7

Very few

available

More than enough available

2. I rarely encounter desirable men/women who are available for a long-term relationship.
1
2
3
4
5
6
7

Strongly

Strongly

Disagree

Agree

3. It is hard to find single men/women whom I would like to date.

\section{1}

Strongly

Disagree
2

3
4

5

6

7 Strongly

Agree 
4. How many single men/women around your age do you typically encounter in your day-to-day life? (Please base your answer solely on how many eligible men/women you meet, regardless of whether or not these individuals would make desirable partners).

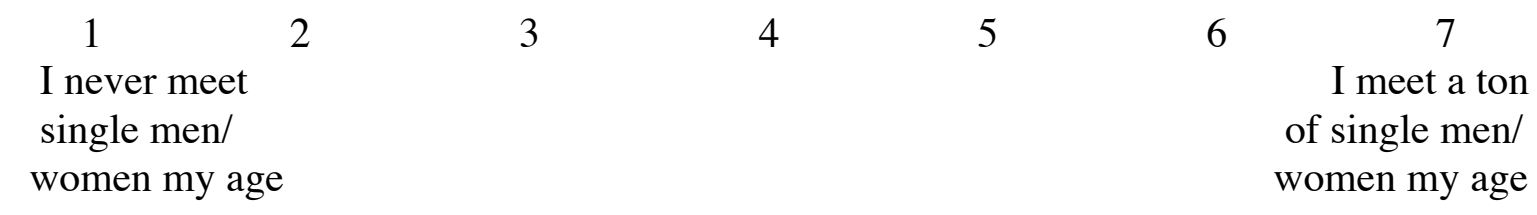

5. In general there are a quite a few men/women available who I could potentially pursue for a long-term relationship (e.g., who are single, of an appropriate age, etc.).
12
3
4
5
6
7
Strongly
Disagree
Agree

Strongly

6. There are a lot of single men/women around my age in my community.
1
2
3
4
5
6
7
Disagree
Strongly
Agree

Strongly

Single item assessing the global quality of available partners:

7. Most of the single men/women I meet have the qualities people generally look for in a spouse.

$\begin{array}{lllllll}1 & 2 & 3 & 4 & 5 & 6 & 7\end{array}$

Strongly

Strongly

Disagree Agree 


\section{Peer-reported}

1. In general, how available are single men/women in [Participant name]'s community who would make good marriage partners?

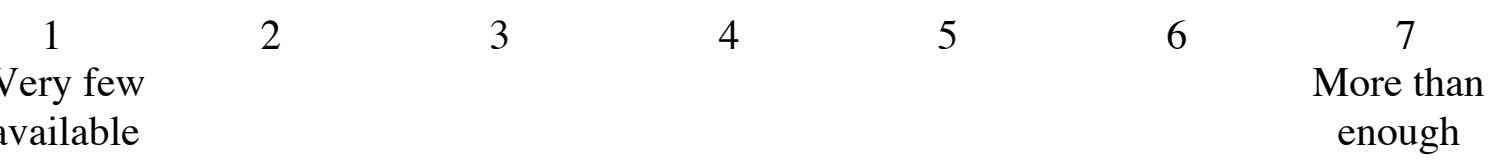

2. [Participant name] rarely encounters desirable men/women who are available for a long-term relationship.

$\begin{array}{lllllll}1 & 2 & 3 & 4 & 5 & 6 & 7\end{array}$

Strongly

Strongly

Disagree

Agree

3. It is hard for [participant name] to find single men/women whom he/she would like to date.

$\begin{array}{lllllll}1 & 2 & 3 & 4 & 5 & 6 & 7\end{array}$

Strongly

Strongly

Disagree

Agree

4. How many single men/women around his/her age does [participant name] typically encounter in his/her day-to-day life? (Please base your answer solely on how many eligible men/women he/she meets, regardless of whether or not these individuals would make desirable partners).

$\begin{array}{llccc}1 \quad 3 & 4 & 5 & 6 & 7 \\ \begin{array}{l}\text { He/she never } \\ \text { meets single men/ } \\ \text { women his/her age }\end{array} & & & \begin{array}{c}\text { He/she meets a } \\ \text { ton of single men/ } \\ \text { women his/her age }\end{array}\end{array}$


5. In general there are a quite a few men/women available who [participant name] could potentially pursue for a long-term relationship (e.g., people who are single, of an appropriate age, etc.).

$\begin{array}{llllllll}1 & 2 & 3 & 4 & 5 & 6 & 7\end{array}$

Strongly

Disagree Strongly

Agree

6. There are a lot of single men/women around [participant name]'s age in his/her community.

$\begin{array}{llllllll}1 & 2 & 3 & 4 & 5 & 6 & 7\end{array}$

Strongly

Strongly

Disagree

Agree

Single item assessing the global quality of available partners:

7. Most of the single men/women [participant name] meets have the qualities people generally look for in a spouse.

1

Strongly

Disagree
3

4

5

6

7

Strongly

Agree 


\section{APPEndix D: DAting SuCCESS}

\section{Section A: Number of Committed Involvements}

1. How many exclusive/committed romantic relationships have you been involved in over the course of your lifetime?

\section{Section B: Duration of Committed Involvements}

1. On average, how long have your exclusive/committed romantic relationships lasted?
a. Less than 6 months
b. 6 months to a year
c. 1 to 2 years
d. 2 to 3 years
e. 3 to 4 years
f. 4 to 5 years
g. Over 5 years

2. How long was the longest exclusive/committed romantic relationship you have ever had?
a. Less than 6 months
b. 6 months to a year
c. 1 to 2 years
d. 2 to 3 years
e. 3 to 4 years
f. 4 to 5 years
g. 5 to 6 years
h. 6 to 7 years
i. 7 to 8 years
j. 8 to 9 years
k. 9 to 10 years
1. More than 10 years 


\section{Section C: Quality of Past Relationships}

1. Overall, how satisfying have your exclusive/committed relationships been compared to most people's committed relationships?

$\begin{array}{ccccccc}1 & 2 & 3 & 4 & 5 & 6 & 7 \\ \begin{array}{l}\text { Much less } \\ \text { satisfying }\end{array} & & \begin{array}{c}\text { About } \\ \text { average }\end{array} & & & \begin{array}{r}\text { Much more } \\ \text { satisfying }\end{array}\end{array}$

2. Most of my past romantic relationships have been a disappointment.

$\begin{array}{llllllll}1 & 2 & 3 & 4 & 5 & 6 & 7\end{array}$

Strongly

Disagree

3. My past relationships have been filled with conflict.

$\begin{array}{llllllll}1 & 2 & 3 & 4 & 5 & 6 & 7\end{array}$

Strongly

Disagree

Strongly

Agree

\section{Section D: Dating Satisfaction}

1. I am satisfied with the current state of my love life.

$\begin{array}{ccccccc}1 & 2 & 3 & 4 & 5 & 6 & 7 \\ \begin{array}{l}\text { Strongly } \\ \text { Disagree }\end{array} & & & & & \text { Strongly } \\ \text { Agree }\end{array}$




\section{APPENDIX E: RELATIONSHIP QUALITY}

\section{Section A: Relationship Satisfaction (Murray, Holmes, Dolderman, \& Griffin, 2000)}

Using the scale below, please indicate how true each of the following statements is of your relationship with [partner name].

$\begin{array}{ccccccccc}1 & 2 & 3 & 4 & 5 & 6 & 7 & 8 & 9 \\ \begin{array}{c}\text { Not at all } \\ \text { true }\end{array} & & & \begin{array}{c}\text { Somewhat } \\ \text { true }\end{array} & & & \begin{array}{c}\text { Completely } \\ \text { true }\end{array}\end{array}$

1. I am extremely happy with my current romantic relationship.

2. I have a very strong relationship with [partner name].

3. I do not feel that my current relationship is successful.

4. My relationship with [partner name] is very rewarding.

\section{Section B: Dedication Commitment} (Stanley \& Markman, 1992)

Using the scale below, please indicate the extent to which you agree or disagree with each of the following statements about your relationship with [partner name].
1
2
3
4
5
6

Strongly

Disagree

1. I may decide that I want to end this relationship at some point in the future.

2. I want this relationship to stay strong no matter what rough times we may encounter.

3. I want to grow old with [partner name].

4. My relationship with [partner name] is clearly part of my future life plans.

5. I may not want to be with [partner name] a few years from now.

6. I do not have life-long plans for this relationship. 


\section{Section C: Relationship Ambivalence}

Using the scale below, please indicate the extent to which you agree or disagree with each of the following statements about your relationship with [partner name].

$\begin{array}{lllllll}1 & 2 & 3 & 4 & 5 & 6 & 7\end{array}$

Strongly

Strongly

Disagree

Agree

1. I feel somewhat confused about my feelings toward [partner name].*

2. I worry about losing some of my independence by getting involved with [partner name].*

3. I am not sure if I want to continue my relationship with [partner name].*

4. I sometimes feel that [partner name] demands or requires too much of my time and attention.*

5. I am confident that [partner name] is the right partner for me.

6. Sometimes I wish that I had not gotten into this relationship.

*Denotes item adapted from Braiker \& Kelley's (1979) relationship ambivalence scale 


\section{APPENDIX F: EXPECTATIONS TO MARRY}

\section{Section A: General Marriage Expectations}

1. On a scale from 0 to 10 - where 0 is "no chance" and 10 is " $100 \%$ chance" - how likely do you think it is that you will eventually (re)marry?

\begin{tabular}{|c|c|c|c|c|c|c|c|c|c|c|}
\hline 0 & 1 & 2 & 3 & 4 & 5 & 6 & 7 & 8 & 9 & 10 \\
\hline $\begin{array}{c}0 \% \\
\text { chance }\end{array}$ & $10 \%$ & $20 \%$ & $30 \%$ & $40 \%$ & $\begin{array}{c}50 \% \\
\text { chance }\end{array}$ & $60 \%$ & $70 \%$ & $80 \%$ & $90 \%$ & $\begin{array}{l}100 \% \\
\text { chance }\end{array}$ \\
\hline
\end{tabular}

2. I am positive that I will get (re)married someday.

$\begin{array}{lllllll}1 & 2 & 3 & 4 & 5 & 6 & 7\end{array}$

Strongly

Disagree

\section{Section B: Expectation to Marry Current Partner}

1. On a scale from 0 to 10 - where 0 is "no chance" and 10 is " $100 \%$ chance" - how likely do you think it is that you and [partner name] will get married?

\begin{tabular}{|c|c|c|c|c|c|c|c|c|c|c|}
\hline 0 & 1 & 2 & 3 & 4 & 5 & 6 & 7 & 8 & 9 & 10 \\
\hline $\begin{array}{c}0 \% \\
\text { chance }\end{array}$ & $10 \%$ & $20 \%$ & $30 \%$ & $40 \%$ & $\begin{array}{l}50 \% \\
\text { chance }\end{array}$ & $60 \%$ & $70 \%$ & $80 \%$ & $90 \%$ & $\begin{array}{l}100 \% \\
\text { chance }\end{array}$ \\
\hline
\end{tabular}

2. There is no doubt in my mind that [partner name] and I will get married someday.
1
2
3
4
5
6
7

Strongly

Disagree

Strongly

Agree 


\section{APPENDIX G: INVESTMENT IN MARRYING}

\section{Section A: Psychological Investment}

The following questions concern your views about marrying. To answer them, think about marriage itself, as much as possible, without considering your relationship with a particular partner.

$\begin{array}{ccccccc}1 & 2 & 3 & 4 & 5 & 6 & 7 \\ \text { Strongly } & & & & & \text { Strongly } \\ \text { Disagree } & & & & & \text { Agree }\end{array}$

1. I can't wait to get married.

2. I feel I will have achieved a major life goal when I get married

3. Getting married is not one of my top priorities

4. I will be extremely disappointed if I never get (re)married.

5. Establishing a happy, healthy marriage is one of the most important things in life.

6. It is better to be married than to go through life being single.

7. My life would be more fulfilling if I were married.

8. It would be very difficult for me to adjust to married life.

\section{Section B: Behavioral Investment}

1. I am actively looking for a partner who would make a good spouse.

$\begin{array}{llllllll}1 & 2 & 3 & 4 & 5 & 6 & 7\end{array}$

Strongly

Strongly

Disagree

Agree

2. I put a lot of effort into looking for a partner who I would like to marry.

$\begin{array}{ccccccc}1 & 2 & 3 & 4 & 5 & 6 & 7 \\ \text { Strongly } & & & & & \text { Strongly } \\ \text { Disagree } & & & & & \text { Agree }\end{array}$


3. In the past YEAR, which of the following methods have you used to try to meet potential romantic partners? (Check all that apply)

a. Engaged in co-ed leisure activities (e.g., joined a co-ed soccer team, took a dance class)

b. Participated in organized social groups (e.g., church bible study, book club)

c. Went speed dating

d. Signed up for a free Internet dating service (e.g., plentyoffish.com)

e. Signed up for a paid Internet dating service (e.g., eHarmony.com, match.com)

f. Had a friend set you up with someone (e.g., went on a "blind date")

g. Visited bars or clubs

For each item individuals checked, they then were asked to indicate the frequency with which they used that method in the past year, using the following format:

4. In the past YEAR, how often did you visit bars or clubs to try to meet potential partners?

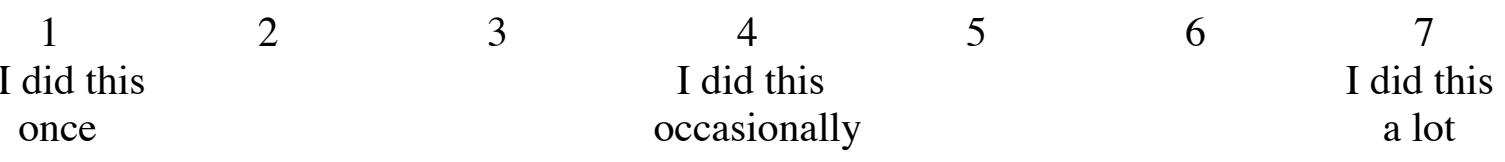

\section{Section C: Interest in Dating and Dating Behavior}

Single item assessing interest in dating:

1. I am not interested in dating at this point in time.

$\begin{array}{ccccccc}1 & 2 & 3 & 4 & 5 & 6 & 7 \\ \text { Strongly } & & & & & \text { Strongly } \\ \text { isagree } & & & & & \text { Agree }\end{array}$

Single item assessing dating behavior:

2. As best as you can remember, how many dates have you been on in the past year? 


\section{APPENDix H: CONTROL VARIABLES}

\section{Section A: Dispositional Optimism}

Using the scale below, please indicate the extent to which you agree or disagree with each of the following statements.

1

Strongly

Disagree

\section{2}

3
4 5 Strongly Agree

1. In uncertain times, I usually expect the best.

2. If something can go wrong for me, it will.

3. I'm always optimistic about my future.

4. I hardly ever expect things to go my way.

5. I rarely count on good things happening to me.

6. Overall, I expect more good things to happen to me than bad.

\section{Section B: Self-esteem}

Using the scale below, please indicate the extent to which you agree or disagree with each of the following statements.
1
2
3
4
5

Strongly

Disagree

1. I feel that I'm a person of worth, at least on an equal plane with others.

2. I feel that I have a number of good qualities.

3. All in all, I am inclined to feel that I am a failure.

4. I am able to do things as well as most other people.

5. I feel I do not have much to be proud of.

6. I take a positive attitude toward myself.

7. On the whole, I am satisfied with myself.

8. I wish I could have more respect for myself.

9. I certainly feel useless at times.

10. At times I think I am no good at all. 


\section{Section C: Attachment Anxiety}

Using the scale below, please indicate the extent to which you agree or disagree that each statement describes how you typically feel in romantic relationships.

$\begin{array}{llllllll}1 & 2 & 3 & 4 & 5 & 6 & 7\end{array}$

Strongly

Strongly

Disagree

Agree

1. I worry that romantic partners won't care about me as much as I care about them.

2. My desire to be very close sometimes scares people away.

3. I need a lot of reassurance that I am loved by my partner.

4. I rarely worry about being abandoned.

5. I find that my partner(s) don't want to get as close as I would like.

6. I get frustrated if romantic partners are not available when I need them.

\section{Section D: Standard Salience}

Please use the scale below to indicate how much you agree or disagree with each of the following statements.
1
2
3
4
5
6

Strongly

Disagree

Agree

1. I know exactly what I want in a marriage partner.

2. If someone asked me, I could easily describe what traits are important to me in a long-term partner.

3. I have talked to friends or relatives about the characteristics I am looking for in a partner.

4. I have given a lot of thought to the qualities I want in a partner.

\section{Section E: Standard Flexibility}

1. If I loved someone, I would be willing to marry him/her even if he/she did not meet some of my criteria for a marriage partner.
1
2
3
4
5
6
7

Strongly

Strongly

Disagree

Agree 


\section{References}

Aiken, L. S., \& West, S. G. (1991). Multiple regression: Testing and interpreting interactions. Newbury Park, CA: Sage.

Allison, P. D. (2003). Missing data techniques for structural equation modeling. Journal of Abnormal Psychology, 112, 545-557.

Axinn, W. G., \& Thornton, A. (1992). The relationship between cohabitation and divorce. Selectivity or cause influence? Demography, 29, 357-374.

Axinn, W. G., \& Thornton, A. (2000). The transformation in the meaning of marriage. In L. J. Waite, C. Bachrach, M. Hidin, E. Thomson, \& A. Thornton (Eds.), The ties that bind: Perspectives on marriage and cohabitation (pp. 147-165). New York: Aldine de Gruyter.

Barelds, D. P. H., \& Dijkstra, P. (2011). Positive illusions about a partner's personality and relationship quality. Journal of Research in Personality, 45, 37-43.

Baucom, D. H., Epstein, N., Rankin, L. A., \& Burnett, C. K. (1996). Assessing relationship standards: The Inventory of Specific Relationship Standards. Journal of Family Psychology, 10, 72-88.

Becker, G. S. (1981). A treatise on the family. Cambridge, MA: Harvard University Press.

Bentler, P. M., \& Bonnet, D. G. (1980). Significance tests and goodness of fit in the analysis of covariance structures. Psychological Bulletin, 88, 588-606.

Blau, P. M. (1964). Exchange and power in social life. New York: Wiley.

Bollen, K. A. (1989). Structural equations with latent variables. Oxford, England: Wiley. 
Braiker, H. B., \& Kelley, H. H. (1979). Conflict in the development of close relationships. In R. L. Burgess \& T. L. Huston (Eds.), Social exchange in developing relationships (pp. 135-168). New York: Academic Press.

Bredow, C. A., \& Huston, T. L. (November, 2009). Wanting more than you can get: The role of minimum mate standards in partnering. Paper presented at the National Council on Family Relations Annual Meeting, San Francisco, CA.

Bredow, C. A., Huston, T. L., \& Glenn, N. D. (2011). Market value, quality of the pool of potential mates, and singles' confidence about marrying. Personal Relationships, 18, 39-57.

Brown, S. (2000). Union transitions among cohabiters: The significance of relationship assessments and expectations. Journal of Marriage and the Family, 62, 833-846.

Brown, M. W., \& Cudeck, R. (1993). Alternative ways of assessing model fit. In K. A. Bollen, \& J. S., Long (Eds.), Testing structural equation models (pp. 132-162). Beverly Hills, CA: Sage.

Bulcroft, R. A., \& Bulcroft, K. A. (1993). Race differences in attitudinal and motivational factors in the decision to marry. Journal of Marriage and the Family, 55, 338355 .

Buss, D. M. (1988). The evolution of human intrasexual competition: Tactics of mate attraction. Journal of Personality and Social Psychology, 54, 616-628.

Buss, D. M. (1989). Sex differences in human mate preferences: Evolutionary hypothesis tested in 37 cultures. Behavioral and Brain Sciences, 12, 1-49.

Buss, D. M. (1994). The evolution of desire. New York: Basic Books.

Buss, D. M., Shackelford, T. K., Kirkpatrick, L. A., \& Larsen, R. J. (2001). A half century of mate preferences: The cultural evolution of values. Journal of Marriage and Family, 63, 491-503. 
Buunk, B. P., \& Van Yperan, N. W. (1991). Referential comparisons, relational comparisons, and exchange orientation: Their relation to marital satisfaction. Personality and Social Psychology Bulletin, 17, 709-717.

Campbell, L., Simpson, J. A., Kashy, D. A., \& Fletcher, G. J. O. (2001). Ideal standards, the self, and flexibility of ideals in close relationships. Personality and Social Psychology Bulletin, 27, 447-462.

Carlson, M., McLanahan, S., \& England, P. (2004). Union formation in fragile families. Demography, 41, 237-261.

Carver, C. S. \& Scheier, M. F. (1998). On the self-regulation of behavior. New York: Cambridge University Press.

Cherlin, A. J. (2004). The deinstitutionalization of American marriage. Journal of Marriage and Family, 66, 848-861.

Clarkberg, M., Stolzenberg, R. M., \& Waite, L. J. (1995). Attitudes, values, and entrance into cohabitational versus marital unions. Social Forces, 74, 609-632.

Cobb, N. P., Larson, J. H., \& Watson, W. L. (2003). Development of the Attitudes about Romance and Mate Selection Scale. Family Relations, 52, 222-231.

Cohen, J. (1988). Statistical power for the behavioral sciences $\left(2^{\text {nd }}\right.$ ed.). Hillsdale, NJ: Erlbaum.

Connelly, B. S., \& Ones, D. S. (2010). An other perspective on personality: Metaanalytic integration of observers' accuracy and predictive validity. Psychological Bulletin, 136, 1092-1122.

Coontz, S. (2005). Marriage, a history. New York: Viking.

Cosmides, L., \& Tooby, J. (1992). Cognitive adaptations for social exchange. In J. H. Barkow, L. Cosmides, \& J. Tooby (Eds.), The adapted mind: Evolutionary 
psychology and the generation of culture (pp. 163-228). New York: Oxford University Press.

Dalton, S. T. (1992). Lived experiences of never-married women. Issues in Mental Health Nursing, 13, 69-80.

Eastwick, P. W., \& Finkel, E. J. (2008). Sex differences in mate preferences revisited: Do people know what they initially desire in a romantic partner? Journal of Personality and Social Psychology, 94, 245-264.

Eastwick, P. W., Finkel, E. J., \& Eagly, A. H. (2011). When and why do ideal partner preferences affect the process of initiating and maintaining romantic relationships? Journal of Personality and Social Psychology, 101, 1012-1032..

Edin, K. (2000). What do low-income single mothers say about marriage? Social Problems, 47, 112-133.

Edin, K., \& Kefalas, M. J. (2005). Promises I can keep: How poor women put motherhood before marriage. Berkeley: University of California Press.

Edwards, J. N. (1969). Familial behavior as social exchange. Journal of Marriage and the Family, 31, 518-526.

Figuerdo, A. J., Sefcek, J. A., \& Jones, D. N. (2006). The ideal romantic partner personality. Personality and Individual Differences, 41, 431-441.

Finkel, E. J., Eastwick, P. W., \& Matthews, J. (2007). Speed-dating as an invaluable tool for studying romantic attraction: A methodological primer. Personal Relationships, 14, 149-166.

Fletcher, G. J. O., Simpson, J. A., \& Thomas, G. (2000). Ideals, perceptions, and evaluations in early relationship development. Journal of Personality and Social Psychology, 79, 933-940. 
Fletcher, G. J. O., Simpson, J. A., Thomas, G., \& Giles, L. (1999). Ideals in intimate relationships. Journal of Personality and Social Psychology, 76, 72-89.

Gibson-Davis, C. M., Edin, K., \& McLanahan, S. (2005). High hopes but even higher expectations: The retreat from marriage among low-income couples. Journal of Marriage and Family, 67, 1301-1312.

Goldstein, J. R., \& Kenney, K. T. (2001). Marriage delayed or marriage forgone? New cohort forecasts of first marriage for U.S. women. American Sociological Review, 66, 506-519.

Heckhausen, J., \& Schultz, R. (1995). A life-span theory of control. Psychological Review, 102, 284-304.

Hofstee, W. K. B. (1994). Who should own the definition of personality? European Journal of Personality, 8, 149-162.

Hogan, R. (1998). Reinventing personality. Journal of Social and Clinical Psychology, $17,1-10$.

Hu, L. T., \& Bentler, P. M. (1999). Cutoff criteria for fit indexes in covariance structure analysis: Conventional criteria versus new alternatives. Structural Equation Modeling, 6, 1-55.

Huston, T. L. (2001). Constructs measured in the PAIR Project. Unpublished manual.

Iyengar, S. S., Simonson, I., Fisman, R., \& Mogilner, C. (2005, January). I know what I want but can I find it? Examining the dynamic relationship between stated and revealed preferences. Paper presented at the Society for Personality and Social Psychology Annual Meeting, New Orleans, LA.

Jensen-Campbell, L. A., Graziano, W. G., \& West, S. G. (1995). Dominance, prosocial orientation, and female preferences: Do nice guys really finish last? Journal of Personality and Social Psychology, 68, 427-440. 
John, O. P., \& Robins, R. W. (1994). Accuracy and bias in self-perception: Individual differences in self-enhancement and the role of narcissism. Journal of Personality and Social Psychology, 66, 206-219.

Jöreskog, K.G., \& Sörbom, D. (1999). LISREL 8: User's reference guide. Lincolnwood, IL: Scientific Software International.

Kenny, D. A. (2004). PERSON: A general model of interpersonal perception. Personality and Social Psychology Review, 8, 265-280.

Kenny, D. A., \& Judd, C. M. (1984). Estimating the nonlinear and interactive effects of latent variables. Psychological Bulletin, 96, 201-210.

Kenrick, D. T., Groth, G. E., Trost, M. R., \& Sadalla, E. K. (1993). Integrating evolutionary and social exchange perspectives on relationships: Effects of gender, self-appraisal, and involvement level on mate selection criteria. Journal of Personality and Social Psychology, 64, 951-969.

Kirsner, B. R., Figuerdo, A. J., \& Jacobs, W. J. (2003). Self, friends, and lovers: Structural relations among Beck Depression Inventory Scores and perceived mate values. Journal of Affective Disorders, 75, 131-148.

Kline, R. B. (2005). Principles and practice of structural equation modeling ( $2^{\text {nd }}$ ed.). New York: Guilford Press.

Knee, C. R., Nanayakkara, A., Vietor, N. A., Neighbors, C., \& Patrick, H. (2001). Implicit theories of relationships: Who cares if romantic partners are less than ideal? Personality and Social Psychology Bulletin, 27, 808-819.

Kolar, D. W., Funder, D. C., \& Colvin, C. R. (1996). Comparing the accuracy of personality judgments by the self and knowledgeable others. Journal of Personality, 64, 311-337. 
Kurzban, R., \& Weeden, J. (2007). Do advertised preferences predict the behavior of speed daters? Personal Relationships, 14, 623-632.

Lewis, K. G., \& Moon, S. (1997). Always single and single again women: A qualitative study. Journal of Marital and Family Therapy, 23, 115-134.

Li, N. P., Bailey, J. M., Kenrick, D. T., \& Linsenmeier, J. A. W. (2002). The necessities and luxuries of mate preferences: Testing the tradeoffs. Journal of Personality and Social Psychology, 82, 947-955.

Lichter, D. T. (1990). Delayed marriage, marital homogamy, and the mate selection process among white women. Social Science Quarterly, 71, 802-811.

Lichter, D. T., Anderson, R. N., \& Hayward, M. D. (1995). Marriage markets and marital choice. Journal of Family Issues, 16, 412-431.

Lichter, D. T., McLaughlin, D. K., Kephart, G., \& Landry, D. J. (1992). Race and the retreat from marriage: A shortage of marriageable men? American Sociological Review, 57, 781-799.

Lundy, D. E., Tan, J., \& Cunningham, M. R. (1998). Heterosexual romantic preferences: The importance of humor and physical attractiveness for different types of relationships. Personal Relationships, 5, 311-325.

Marsh, H. W., \& Hau, K.-T. (1996). Assessing goodness of fit: Is parsimony always desirable? Journal of Experimental Education, 64, 364-390.

Marsh, H. W., Wen, Z., \& Hau, K. (2004). Structural equation models of latent interactions: Evaluation of alternative estimation strategies and indicator construction. Psychological Methods, 9, 275-300.

McClelland, G. H., \& Judd, C. M. (1993). Statistical difficulties of detecting interactions and moderator effects. Psychological Bulletin, 114, 376-389. 
McDonald, R. P., \& Ho, M. H. R. (2002). Principles and practice in reporting structural equation analyses. Psychological Methods, 7, 64-82.

McLaughlin, D. K., \& Lichter, D. (1997). Poverty and the marital behavior of young women. Journal of Marriage \& the Family, 59, 582-594.

Miller, P. J. E., Niehuis, S., \& Huston, T. L. (2006). Positive illusions in marital relationships: A 13-year longitudinal study. Personality and Social Psychology Bulletin, 32, 1579-1594.

Moffitt, R. (2002). Incentive effects in the U.S. welfare system. Journal of Economic Literature, 30, 1-61.

Morrow, G. D., \& O'Sullivan, C. (1998). Romantic ideals as comparison levels: Implications for satisfaction and commitment in romantic involvements. In V. C. de Munck (Ed.), Romantic love and sexual behavior: Perspectives from the social sciences (pp. 171-199). Westport, CT: Greenwood.

Murray, S. L., Holmes, J. G., Dolderman, D., \& Griffin, D. W. (2000). What the motivated mind sees: Comparing friends' perspectives to married partners' views of each other. Journal of Experimental Social Psychology, 36, 600-620.

Murray, S. L., Holmes, J. G., \& Griffin, D. W. (1996). The benefits of positive illusions: Idealization and the construction of satisfaction in close relationships. Journal of Personality and Social Psychology, 70, 79-98.

Murstein, B. I. (1976). Who will marry whom? Theories and research in marital choice. New York: Springer.

Neff, L. A., \& Karney, B. R. (2002). Judgments of a relationship partner: Specific accuracy but global enhancement. Journal of Personality, 70, 1079-1112. 
Neff, L. A., \& Karney, B. R. (2005). To know you is to love you: The implications of global adoration and specific accuracy for marital relationships. Journal of Personality and Social Psychology, 88, 480-497.

Oppenheimer, V. K. (1988). A theory of marriage timing. American Journal of Sociology, 94, 563-591.

Overall, N. C., Fletcher, G. J. O., \& Simpson, J. A. (2006). Regulation processes in intimate relationships: The role of ideal standards. Journal of Personality and Social Psychology, 91, 662-685.

Paulhaus, D. L. (1998). Interpersonal and intrapsychic adaptiveness of trait selfenhancement: A mixed blessing? Journal of Personality and Social Psychology, 74, 1197-1208.

Penke, L., Todd, P. M., \& Lenton, A. P. (2008). How self-assessments can guide human mating decisions. In G. Geher, \& G. Miller (Eds.), Mating intelligence: Sex, relationships, and the mind's reproductive system (pp. 37-76). New York: Francis and Taylor.

Preacher, K. J., Curran, P. J., \& Bauer, D. J. (2006). Computational tools for probing interaction effects in multiple linear regression, multilevel modeling, and latent curve analysis. Journal of Educational and Behavioral Statistics, 31, 437-448.

Raley, R. K., \& Bratter, J. (2004). Not even if you were the last person on earth!: How marital search constraints affect the likelihood of marriage. Journal of Family Issues, 25, 167-181.

Robins, R. W., \& Beer, J. S. (2001). Positive illusions about the self: Short-term benefits and long-term costs. Journal of Personality and Social Psychology, 80, 340-352.

Rosenberg, M. (1965). Society and adolescent self-image. Princeton, NJ: Princeton University Press. 
Sassler, S., \& Schoen, R. (1999). The effect of attitudes and economic activity on marriage. Journal of Marriage and the Family, 61, 147-159.

Schafer, J. L., \& Graham, J. W. (2002). Missing data: Our view of the state of the art. Psychological Methods, 7, 147-177.

Scheier, M. F., Carver, C. S., \& Bridges, M. W. (1994). Distinguishing optimism from neuroticism (and trait anxiety, self-mastery, and self-esteem): A reevaluation of the Life Orientation Test. Journal of Personality and Social Psychology, 67, 1063-1078.

Schoen, R., \& Standish, N. (2001). The retrenchment of marriage: Results from marital status life tables for the United States, 1995. Population and Development Review, 27, 553-563.

Segrin, C., \& Nabi, R. L. (2002). Does television viewing cultivate unrealistic expectations about marriage? Journal of Communication, 52, 247-263.

Sharp, E. A., \& Ganong, L. H. (2000). Raising awareness about marital expectations: Are unrealistic beliefs changed by integrative teaching? Family Relations, 49, 71-76.

Sharp, E. A., \& Ganong, L. (2007). Living in the gray: Women's experiences of missing the marital transition. Journal of Marriage and Family, 69, 831-844.

Sloman, S., \& Sloman, L. (1988). Mate selection in the service of human evolution. Journal of Social and Biological Structures, 11, 457-468.

Smock, P. J., \& Manning, W. D. (1995, August). Dyadic decisions: Which cohabiting couples marry? Paper presented at the annual meeting of the American Sociological Association, Washington, DC.

Sprecher, S., \& Regan, P. C. (2002). Liking some things (in some people) more than others: Partner preferences in romantic relationships and friendships. Journal of Social and Personal Relationships, 19, 463-481. 
Stanley, S. M., \& Markman, H. J. (1992). Assessing commitment in personal relationships. Journal of Marriage and the Family, 54, 595-608.

Taylor, S. E., \& Brown, J. D. (1988). Positive illusions: Creative self-deception and the healthy mind. New York: Basic Books.

Todd, P. M., Penke, L., Fasolo, B., \& Lenton, A. P. (2007). Different cognitive processes underlie human mate choices and mate preferences. Proceedings of the National Academy of Sciences, 104, 15011-15016.

Urbaniak, G. C., \& Kilmann, P. R. (2006). Niceness and dating success: A further test of the nice guy stereotype. Sex Roles, 55, 209-224.

Van Lange, P. A. M., \& Rusbult, C. E. (1995). My relationship is better than - and not as bad as - yours is: The perception of superiority in close relationships. Personality and Social Psychology Bulletin, 21, 32-44.

Vazire, S. (2006). Informant reports: A cheap, fast, and easy method for personality assessment. Journal of Research in Personality, 40, 472-481.

Vazire, S. (2010). Who knows what about a person? The Self-Other Knowledge Asymmetry (SOKA) Model. Journal of Personality and Social Psychology, 98, 281-300.

Vazire, S. \& Mehl, M. R. (2008). Knowing me, knowing you: The accuracy and unique predictive validity of self-ratings and other-ratings of daily behavior. Journal of Personality and Social Psychology, 95, 1202-1216.

Waller, M. R., \& McLanahan, S. S. (2005). 'His' and 'her' marriage expectations: Determinants and consequences. Journal of Marriage and Family, 67, 53-67.

Wei, M., Russell, D. W., Mallinckrodt, B., \& Vogel, D. L. (2007). The Experiences in Close Relationships Scale (ECR) - Short Form: Reliability, validity, and factor structure. Journal of Personality Assessment, 88. 187-204. 
Weiner, B. (1992). Human motivation: Metaphors, theories, and research. Newbury Park, CA: Sage.

Wilson, W. J. (1987). The truly disadvantaged. Chicago: University of Chicago Press.

Wood, R. G. (1995). Marriage rates and marriageable men: A test of Wilson's hypothesis. Journal of Human Resources, 30, 163-193.

Wrosch, C., Scheier, M. F., Miller, G. E., Schultz, R., \& Carver, C. S. (2003). Adaptive self-regulation of unattainable goals: Goal disengagement, goal reengagement, and subjective well-being. Personality and Social Psychology Bulletin, 29, 14941508.

Zenter, M. R. (2005). Ideal mate personality concepts and compatibility in close relationships: A longitudinal analysis. Journal of Personality and Social Psychology, 89, 242-256. 


\section{Vita}

Carrie Ann Barth Bredow was born in Midland, Michigan in 1983. After graduating from Northview High School in Grand Rapids, Michigan, she attended Central Michigan University and received her B.S. in Family Studies and Psychology in 2005. She entered the Graduate School of the University of Texas at Austin in 2006 and received her M.A. in Human Development and Family Sciences in 2009. After receiving her Ph.D. in Human Development and Family Sciences in the summer of 2012, Carrie will begin a position as an Assistant Professor of Psychology at Hope College in Holland, Michigan.

Permanent email: bredow@hope.edu.

This dissertation was typed by the author. 